\title{
Valve-seat components in a diesel engine: a tribological approach to limit wear
}

\author{
Martial Crozet $^{1}$, Yves Berthier ${ }^{1}$, Aurélien Saulot ${ }^{1, *}$ (D), David Jones ${ }^{2,}$, and Benyebka Bou-Saïd ${ }^{1}$ (D) \\ ${ }^{1}$ Univ Lyon, INSA Lyon, CNRS, LaMCoS, UMR5259, 69621 Villeurbanne, France \\ ${ }^{2}$ Volvo Trucks, Group Trucks Technology Lyon, France
}

Received: 29 June 2021 / Accepted: 19 September 2021

\begin{abstract}
Within diesel engines, the valve-seat contact is one of the few non-lubricated contacts which is subjected to significant degradation. This degradation is put in evidence by material removal at the intake valve. The material pull out is promoted by the replication of combustion cycles (500 million) and severe operating conditions (pressure $18 \mathrm{MPa}$ ). The wear can lead to gas leakage and engine failure. The target of this work was to identify the main parameters affecting this wear. Our approach was based on the tribological triplet and material flows within the contact involving both numerical and experimental approaches. A dynamic model and a valvetrain test bench showed that the wear flows could be activated by the architecture of the valve opening system. Consequently, the limitation of these flows can be obtained by controlling the "global" geometry of the system and therefore without modifying the properties of the materials. In the same way, a finite element model of the local response of the seat-valve contact highlighted the impact of the "local" geometry of the contact. The change of this geometry is a lever to limit the shearing forces which reduces the tearing of the particles and therefore wear. Finally, tests carried out on the engine and on a specifically adapted test bench completed the understanding of degradation mechanisms (source flow, wear flow, etc.). Morphological interpretations of worn surfaces in terms of material flows allowed the understanding of the build-up stages of a protective layer. One solution to promote this internal flow is the use of pollutants from combustion. For example, the burned oil in contact, which is a priori harmful, becomes an opportunity here. In addition, un-burned hydrocarbons from the combustion of biodiesel help to protect the contact.
\end{abstract}

Keywords: Non lubricated contact / wear / engine / tribological triplet / material flows

\section{Introduction}

Valve motion induced by the valve train enables the flow of inlet and exhaust gas within the engine (Fig. 1). The valveseat contact is a complex area. Many parameters are involved: mechanical stress, thermal gradients, combustion environment...

The valve-seat contact is in the cylinder head close to the combustion chamber. The operation of the diesel engine is characterized by 4 phases (Fig. 2). It allows the conversion of the chemical energy resulting from the combustion of fuel into mechanical energy via the displacement of the piston in the cylinder.

\footnotetext{
* e-mail: aurelien.saulot@insa-lyon.fr
}

\subsection{Problems: industrial point of view}

In the diesel engine, valves and seats are components which must fulfil their roles throughout the entire life of the vehicle. More precisely, in the case of trucks they must resist during at least $600,000 \mathrm{~km}$ which correspond to almost 500 million contact actuations. To respect the evolution of environmental standards [1] on the valve-seat contact durability, truck manufacturers are commonly using engine long duration tests $(\approx 1000 \mathrm{~h})$. In some cases (Fig. 3 ), valves or seats are submitted to major material removal.

Degradation of the contact between the valve and the seat results in a reduction in the valve lift which no longer allows the gas supply and evacuation. In addition, in the closed position, this removal of material leads to an increase in the size of the combustion chamber and may be the cause of imperfect sealing of the chamber, at the same 


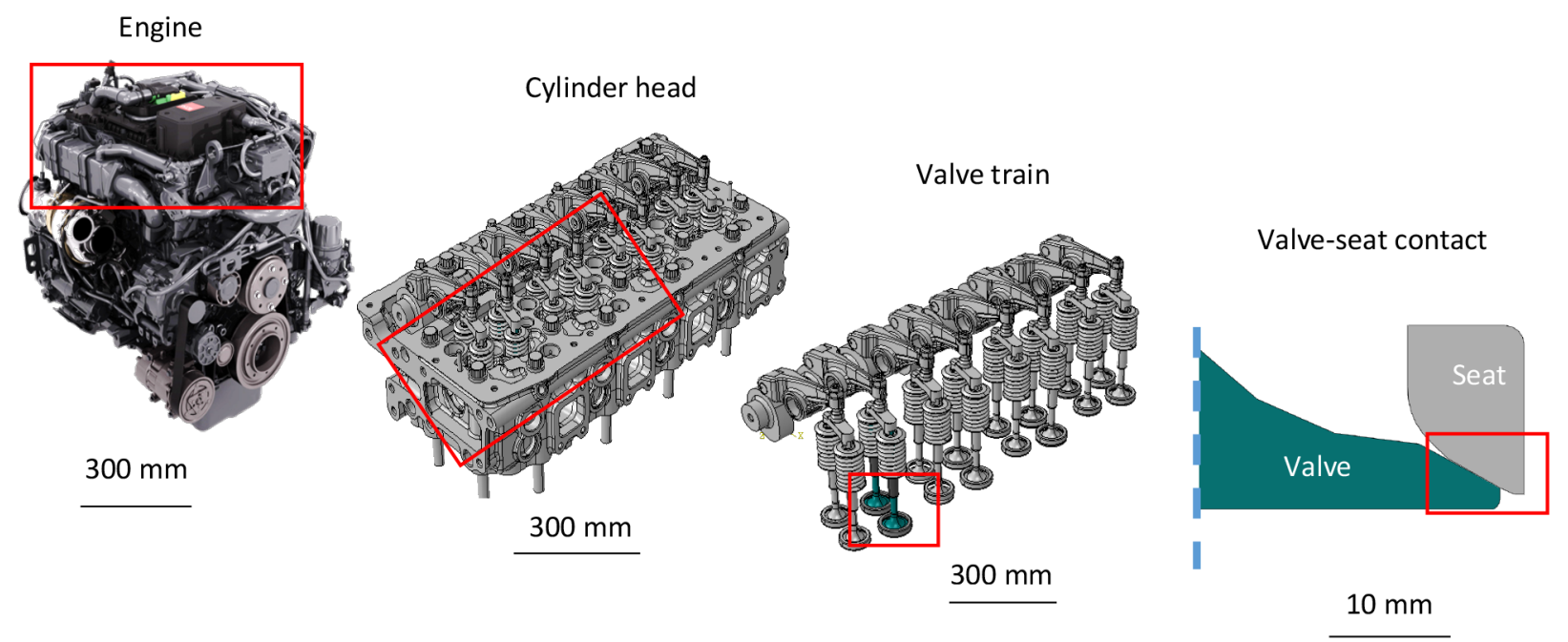

Fig. 1. Location of the valve-seat contact in between the engine (Turbocharged in-line engine, 4 cylinders, 5 litres, 16 valves).

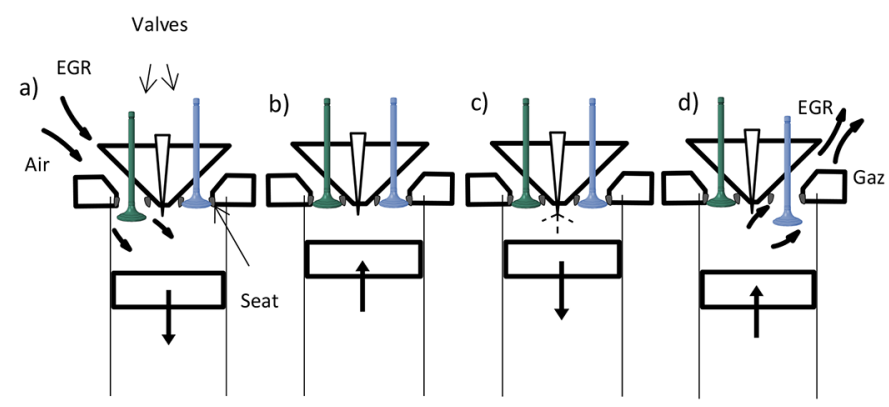

Fig. 2. 4-stroke diesel engine cycle highlighting the valve motion. a: inlet, b: compression, c: expansion-explosion, d: exhaust.
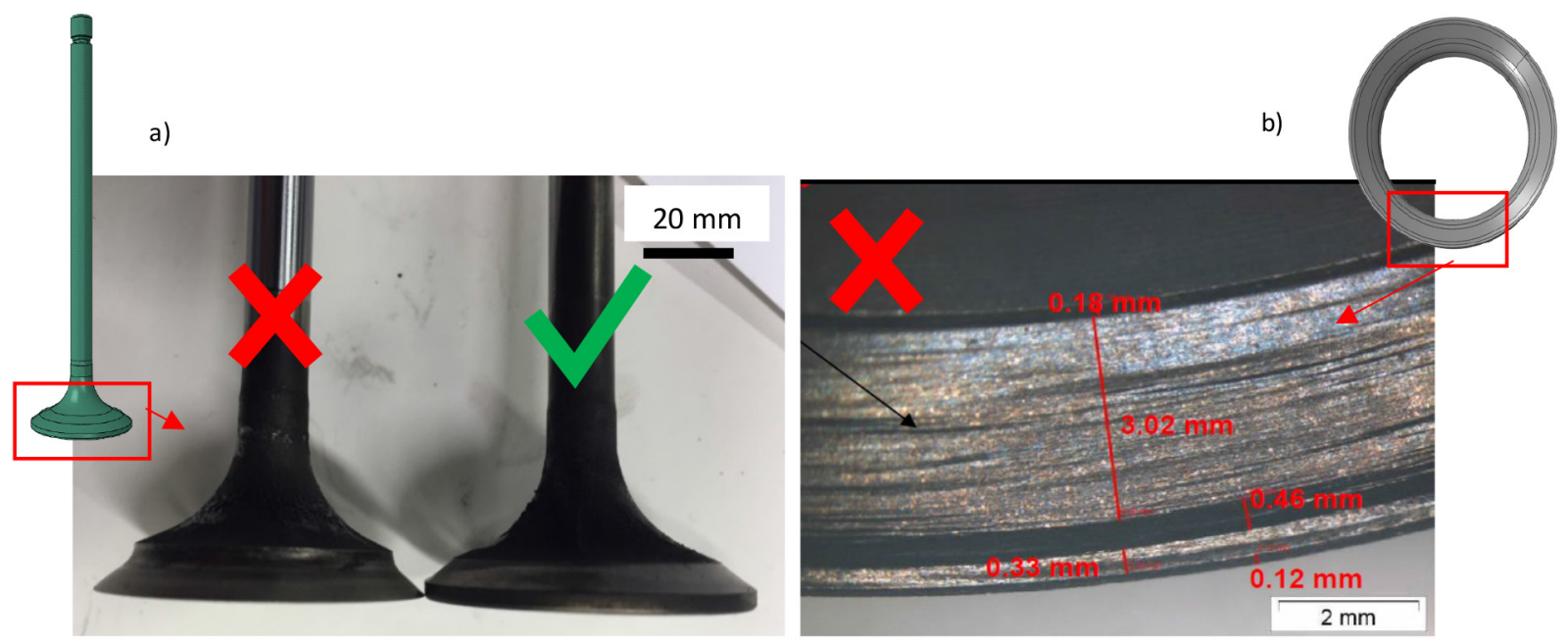

Fig. 3. (a) Valve worn surface compared with an unworn surface; (b) seat worn surface.

time creating hot spots. The short-term consequences are reduced engine fuel efficiency and increased pollution.

The limitation of these long-term tests is the difficulty in understanding the wear mechanisms due to the large scale of engine speed used. To overcome this problem two approaches are conventionally implemented. The first is to experimentally modify the materials of the valves and seats. The second is to change the system parameters via numerical models.

When conditions become too severe for seat-valve contact, one solution is to modify the material. But resistance to tearing, corrosion, abrasion or even fatigue 
is studied separately. Corrosion resistance is discussed in $[2,3]$. In the simplest case, the thickness and the formation of oxides on the surface of the material are determined after an exposure time in an atmosphere at different temperatures. This method is simple to implement and allows the materials to be tested individually. However, this shows a weakness. The first is the combustion environment which is not representative. The second is that the material considered to be the most in phase with the application is the one which oxidizes the least. As demonstrated in [4] in the case of contact activation, oxides under certain temperature conditions can reduce wear. The configuration of the test (with or without contact) has a direct influence on the material behaviour. Numerous publications described test benches dedicated to the valve-seat contact [2,5-12]. In all cases different valve materials are tested in front of a seat material. This solution allows pairs of materials to be tested together. However, the degradation levels are a result of the operating conditions of the contact within the test bench.

Finally, the latest analyses of the materials present in the literature are carried out on the engine itself [13-17]. These analyses either exploit the breakdown of a vehicle and therefore deal with engine damage, or come from durability tests carried out in the engine and are therefore the result of the operating conditions. In addition, engine testing is expensive and cannot focus solely on seat-valve contact materials.

The "material" approach is used as part of a postdevelopment validation and does not allow an understanding of the degradation mechanisms under normal operating conditions. To cope with the difficulties of implementing material tests during the development phases, the second strategy is numerical modelling.

The main objective of numerical modelling is to find a simple criterion to limit the levels of wear. The articles on this aspect can be divided into 3 categories: dynamic studies involving the whole system, those dealing only with the seat-valve contact (by finite elements) and finally those using Archard's law in a local analytical model.

The dynamic modelling of the valve train system involves the rigid body type approach [18-22]. With this approach, results can be obtained in agreement with the experimental measurements. From these analyses, it appears that it is impossible to link the response of the system to a quantification of the wear of the seat-valve contacts.

With a local model (by finite elements for example) we can characterize the behaviour of the valve and the seat throughout the engine cycle. Two phenomena are discussed in the literature:

- The temperature distribution in the valve.

- The distribution of stresses in the valve and/or the seat as a function of the attack contact angle.

The temperature distribution is discussed in [23-27]. However, the boundary conditions being complex within the engine, digital models only allow access to orders of magnitude. In the literature one also finds works which deal directly with the quantification of wear. The authors $[28,29]$ refer to Archard's law. The wear coefficients extracted from the individual tests are used. However,

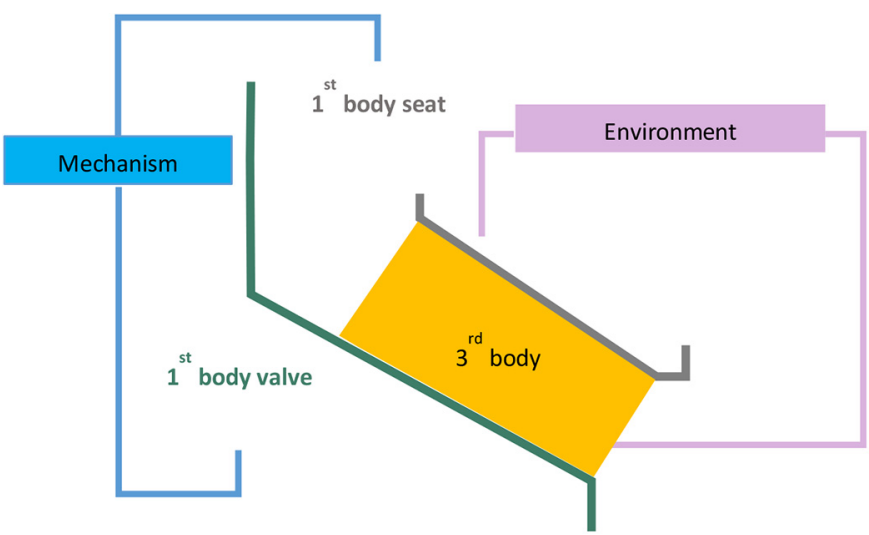

Fig. 4. Tribological definition of the valve-seat contact [30].

the use of a wear coefficient extracted from nonrepresentative conditions limits the possibility of carrying out a direct transposition. The approaches found in the literature provide interesting information on the operating conditions of the seat-valve contact. However, it is very difficult to make a link between the different works. Indeed, through the procedures put in place, the results seem incomplete or only applicable to a given operating condition. The difficulty of extracting a methodology to understand the wear mechanisms of the valve-seat contact and therefore to envisage an improvement highlights the need for a tribological approach.

\subsection{The tribological methodology}

In this article, a tribological approach is proposed for the valve-seat contact in order to suggest solutions to reduce the degradation of this area and optimize the durability of the engines and thus increase their profitability.

In tribology, contact is made up of 4 fundamental elements (Fig. 4):

- The two $1^{\text {st }}$ bodies which are the valve and the seat.

- The mechanism that allows the contact to open and close. In this case, it is the valve train which imposes the dynamic response of the contact.

- The environment which is an element playing an important role for the life of the contact. This complex environment in the case of the seat-valve contact is both solid and gaseous.

- The $3^{\text {rd }}$ body which is formed during the life of the contact. It is at the interface between the two $1^{\text {st }}$ bodies. It allows the accommodation of speeds and stresses at the interface to limit the degradation of the two $1^{\text {st }}$ bodies.

To formalize the approach, this paper will be divided in three sections:

- Section 2 covers the analysis of the dynamic contact.

- Section 3 characterizes the local mechanical response of the $1^{\text {st }}$ bodies.

- Section 4, based on Section 2 and Section 3, will formalize the overall $3^{\text {rd }}$ body formation mechanisms resulting from the synergy between the mechanism, the $1^{\text {st }}$ bodies and the environment. 


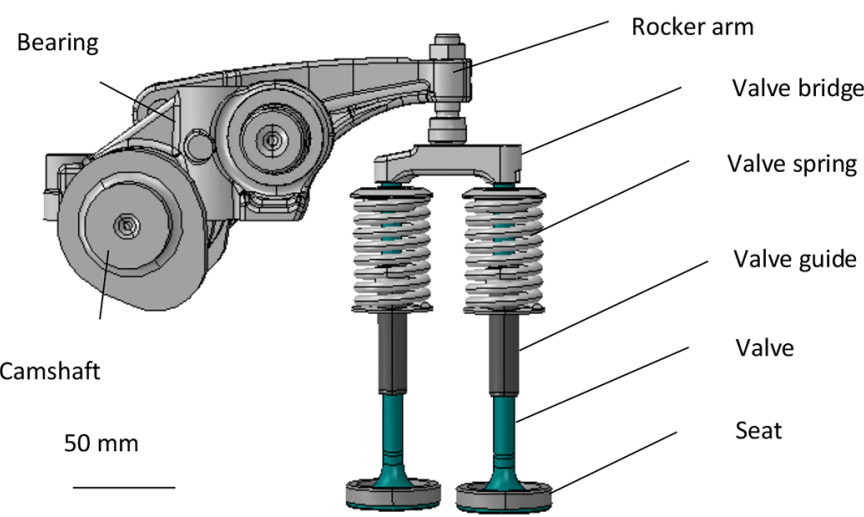

Fig. 5. Description of the valve train for the valve actuation.

\section{The contact dynamic imposed by the valve train}

The valve train is a mechanism that controls the lifting and closing of valves in combustion engines. Different valve train systems are presented in the literature [31]. In this article, for a truck engine, durability is the key parameter. The different parts of the valve train are given in Figure 5.

The camshaft by its eccentric profile transforms a rotational movement into a translational movement. This vertical movement is transformed into a tilting movement via the rocker. Finally, the ball joint (connecting the rocker arm to the valve bridge) and the valve guide lead to the translational movement of the valve. To study the dynamic response of the system, the most representative tool is the engine. However, it is difficult to instrument the valve under operating conditions. A numerical model of a rigid body is thus implemented and validated by a valve train test bench.

\subsection{Numerical and experimental tools}

\subsubsection{ADAMS Rigid body model}

ADAMS software [32] was used because it is relevant for realizing the rigid body model. The kinematic chain described by the model is shown in Figure 6. The different geometries of the parts as well as the assembly dimensions are taken from real engine data. The kinematics extracted is therefore representative of the real geometry of the valve train.

The material data necessary for the ADAMS model are the Young's modulus of the components, the Poisson's ratio and their densities. These characteristics are given for the seat and the valve in Table 1.

The ADAMS rigid body model uses the parameters given in Table 2. The plug-seat contact is considered a mixed contact, therefore a value of 0.2 is taken for the dynamic friction coefficient $\mu$. In addition, Forsberg et al. [33] consider that a value of 0.15 close to 0.2 is relevant even if the coefficient of friction remains unknown under actual engine operating conditions. In the case of the ADAMS model, the damping coefficient corresponds to the energy dissipated numerically in order to avoid a parasitic rebound

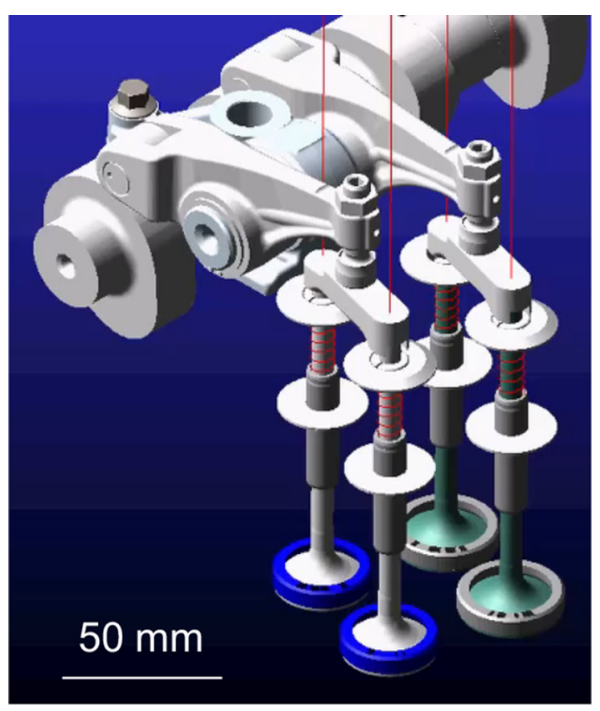

Fig. 6. ADAMS rigid body model.

Table 1. Material properties completed in ADAMS software.

\begin{tabular}{lll}
\hline & $1^{\text {st }}$ body seat & $1^{\text {st }}$ body valve \\
\hline Young's modulus $(\mathrm{GPa})$ & 130 & 210 \\
Poisson's ratio & 0.3 & 0.3 \\
Densities & 6.7 & 7.1 \\
\hline
\end{tabular}

of the valve train. The coefficient of penetration is a maximum value allowed by ADAMS to compensate for the fact that this is only a global approach with rigid bodies.

The actuation of the valve train is achieved by imposing the rotation speed of the camshaft. As shown in Table 3, the speed varies between $450 \mathrm{rpm}$ and $1400 \mathrm{rpm}$. The speed of $450 \mathrm{rpm}$ corresponds to the engine idle speed of $900 \mathrm{rpm}$ and $1400 \mathrm{rpm}$ corresponds to the maximum engine speed of $2800 \mathrm{rpm}$.

Finally, to follow the movement imposed by the camshaft, valves are returned to the closed position using springs which are preloaded during the assembly.

\subsubsection{Valve motion rig}

In the valve motion rig (Fig. 7), the movement is imposed by an electric motor. Thus, it is possible to adjust the rotation speed of the camshaft. In the absence of combustion, the lubrication oil for the valve system is warmed up by heating and external circulation.

Regarding the instrumentation, different elements are put in place such as accelerometers on the fire side of the valves and on the cylinder head to determine the moment of impact of the valve on the seat. The mass of the accelerometers is $2.4 \mathrm{~g}$. Despite this low mass, their influence on the dynamic response of the valve was tested under ADAMS. It has been shown that the valve path is not changed. 
Table 2. Parameters for contact management in the valve train.

\begin{tabular}{lllll}
\hline Contact & Sliding mode & $\mu$ dynamic & Damping $(\%)$ & Penetration $(\mathrm{mm})$ \\
\hline Cam-rocker arm & Impact-sliding & 0.07 & 10 & 0.1 \\
Rocker arm - bridge & Impact & - & 10 & 0.1 \\
Bridge - valve & Impact & - & 10 & 0.1 \\
Valve - guide & Impact-sliding & 0.15 & 10 & 0.1 \\
Valve - seat & Impact-sliding & 0.2 & 10 & 0.1 \\
\hline
\end{tabular}

Table 3. Rotational speeds imposed on the camshaft.

\begin{tabular}{lllllll}
\hline Rotation $(\mathrm{rpm})$ & 450 & 600 & 750 & 900 & 1100 & 1400 \\
\hline
\end{tabular}
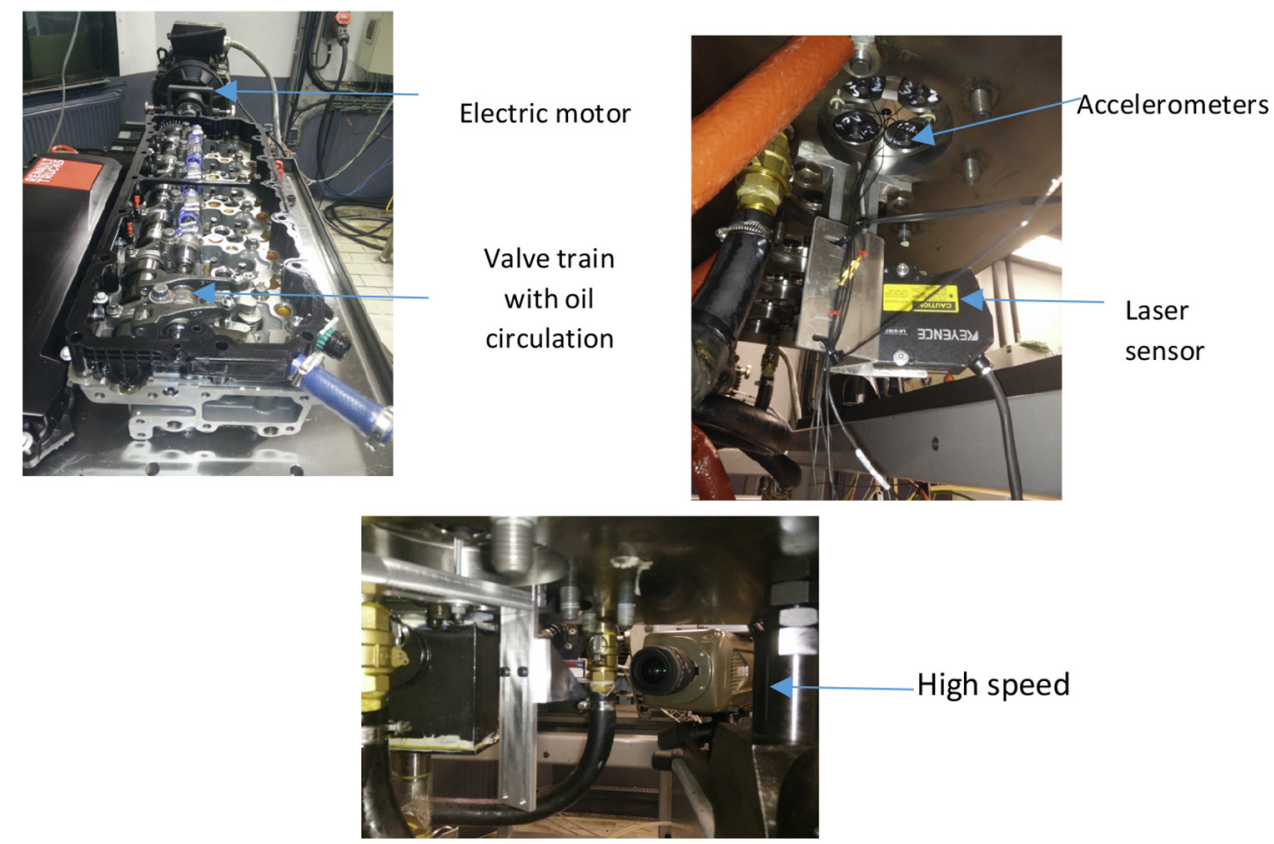

Fig. 7. Valve motion rig used to characterize real valve-seat contact dynamic.

- The vertical displacement of the valve during lifting is measured by a laser sensor. With this measurement we can accurately determine the trajectory of the valve. The derivative of the movement gives access to the valve speed during the impact.

- The valve contact area as well as the valve fire face are observed with the use of a fast camera. Two $45^{\circ}$ mirrors allow these visualizations.

The valve motion rig is representative of the dynamic of the valve train while allowing specific instrumentation unlike the motor itself. The data extracted from the tests must allow firstly to validate the model developed under ADAMS and secondly to access additional information about the real valve-seat contact dynamic.

\subsection{Description of the valve seat contact dynamic}

\subsubsection{Valve-seat contact dynamic through engine life}

To ensure proper engine operation, the valve train controls the response of the valve-seat contact. To this overall description is added the combustion phase, which is however not accessible via rigid body model. Figure 8 summarizes the different phases.

In position 1, the seat-valve contact is in the open position. On admission, the gases (fresh air + exhaust gas recirculation) enter the combustion chamber. In position 2, the geometry of the cam allows the actuation of the spring which returns the valve to the closed position in contact with the seat. This is the impact phase. In position 3 , the valve slides against the seat to its equilibrium position. In 

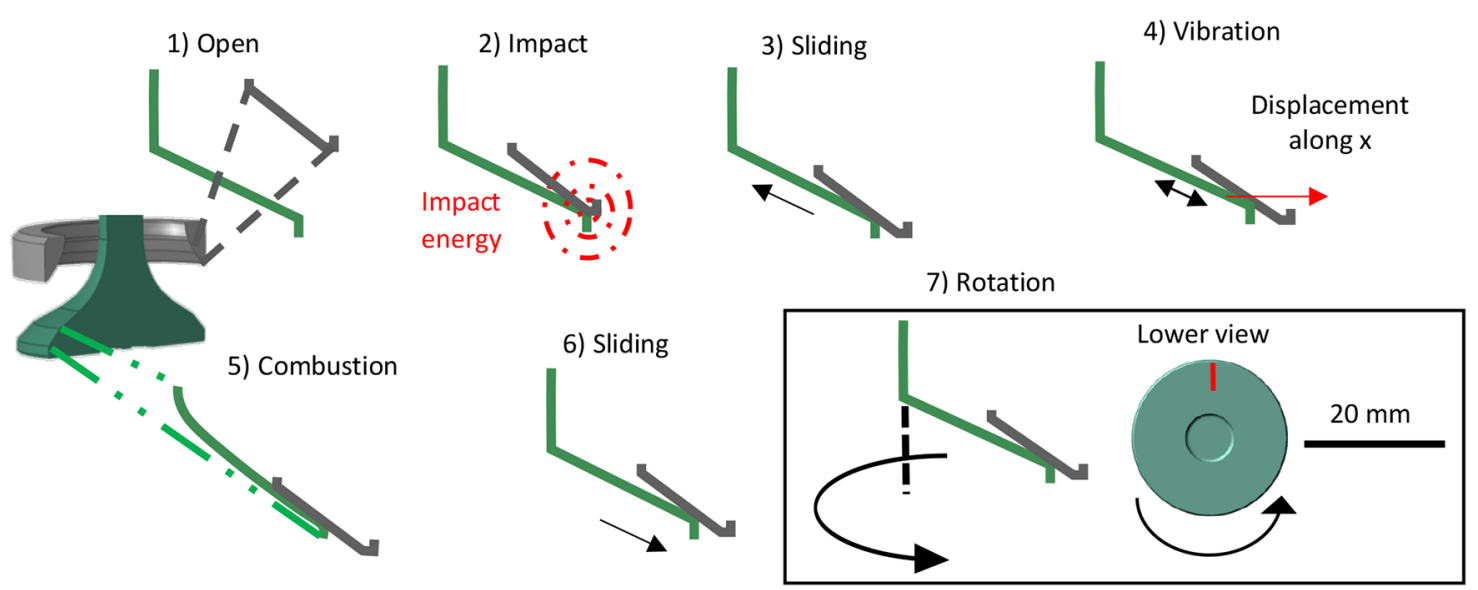

Fig. 8. Valve-seat contact dynamic imposed by the valve train.

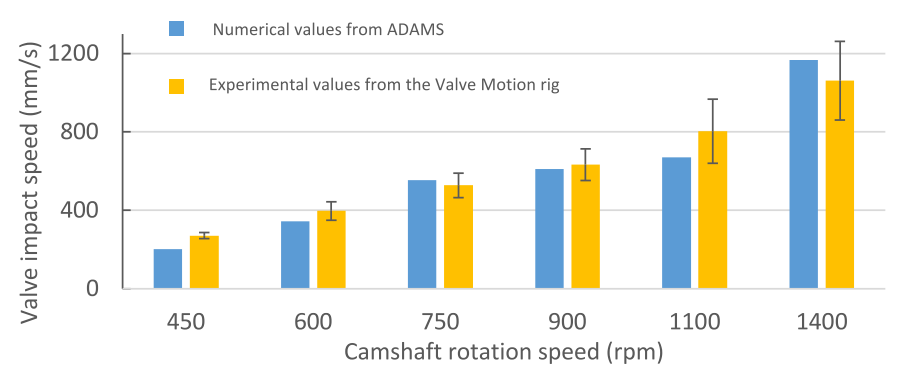

Fig. 9. Valve impact speed on the seat.

position 4, local vibrations between the seat and the valve may appear due to the dynamics of the system. In position 5 , the fire face of the valve is subjected to combustion pressure. This results in a deformation of the valve. In position 6 , the valve slides against the seat. Finally, the movement 7 corresponds to the rotation of the valve around its vertical axis. This phase of rotation occurs in parallel with other stages in the life of the seat-valve contact.

The following paragraphs detail impact, sliding, vibration and rotation phases.

\subsubsection{Impact}

The impact of the valve on its seat is studied in the literature [34-36]. The criterion used is the speed of impact. This speed depends on the geometry of the camshaft. A maximum value found in the literature is $500 \mathrm{~mm} / \mathrm{s}$ [34]. The impact speeds as a function of the camshaft speed are given in Figure 9. These impact speeds are determined with both the rigid body model and the valve movement platform. The clearance between the valve bridge and the rocker arm is set at $0.3 \mathrm{~mm}$ in both cases as recommended in the technical manual. For the rigid body model, the parts are assembled using the coordinates specified on the drawing.

The comparison between the impact velocities of the rigid body model and those of the movement valve validates the consistency of the digital model. It is important to note that for camshaft rotational speeds above

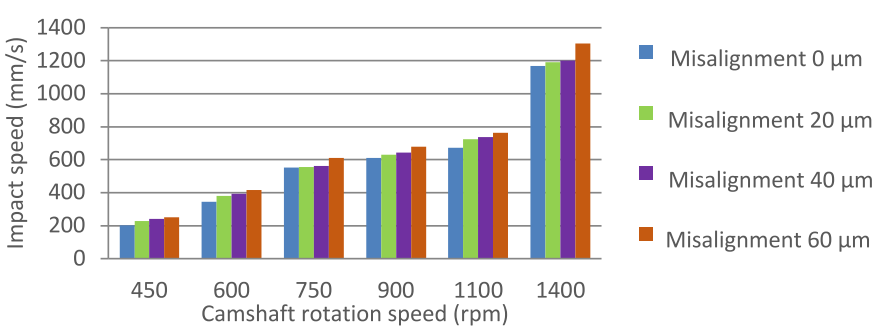

Fig. 10. Controlled seat misalignment relative to valve guide.

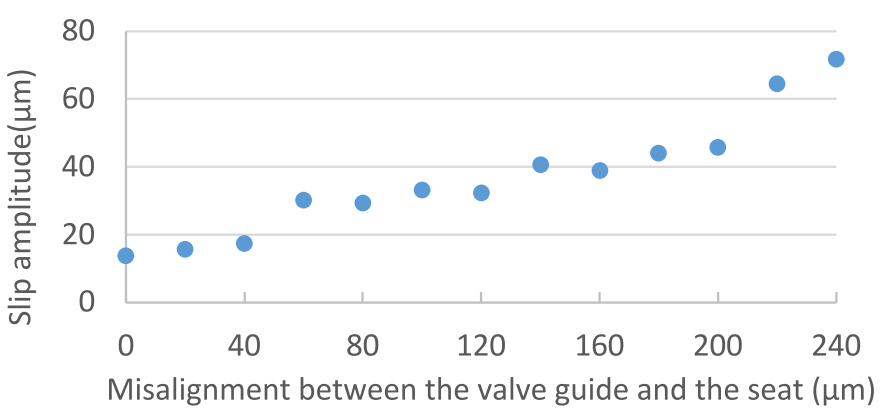

Fig. 11. Amplitude of movement of the valve when sliding against the seat as a function of the misalignment existing between the seat and the valve guide (speed of $600 \mathrm{rpm}$ ).

$750 \mathrm{rpm}$, the valve impact speeds are above $500 \mathrm{~mm} / \mathrm{s}$ (value already declared as a critical criterion). Lewis et al. [35] consider that the increase in the impact velocity of the valve is directly related to the problem of alignment between the valve guide and the seat. To verify this, measurements are taken on a reference cylinder head. In our application, the maximum difference in alignment between the valve center and the seat center is less than $60 \mu \mathrm{m}$. Values varying between 0 and $60 \mu \mathrm{m}$ are introduced into the rigid body model (Fig. 10). This graph shows a slight increase in impact velocity with the establishment of a misalignment. The increase in speed to $1400 \mathrm{rpm}$ generates an increase in kinetic energy from $193 \mathrm{~mJ}$ to $241 \mathrm{~mJ}$ which represents $25 \%$ more energy to be dissipated on impact. 


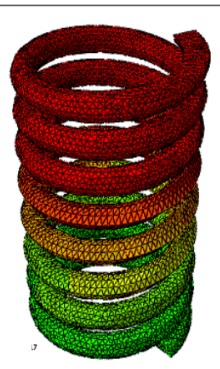

$211 \mathrm{~Hz}$

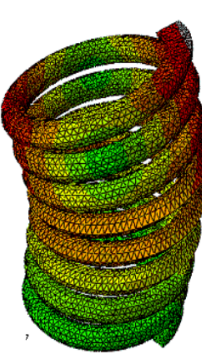

$270 \mathrm{~Hz}$
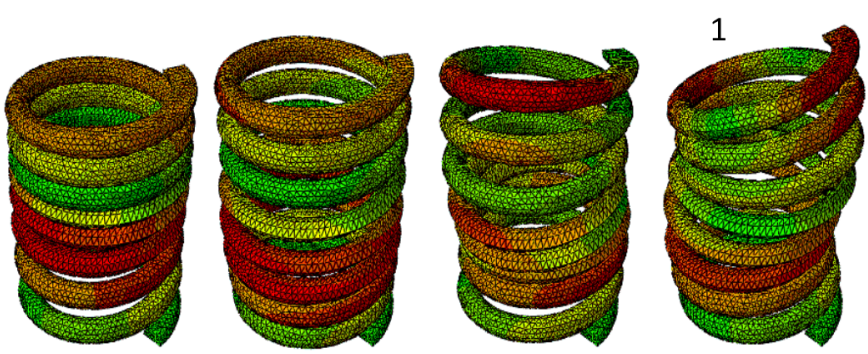

$405 \mathrm{~Hz}$

$358 \mathrm{~Hz}$

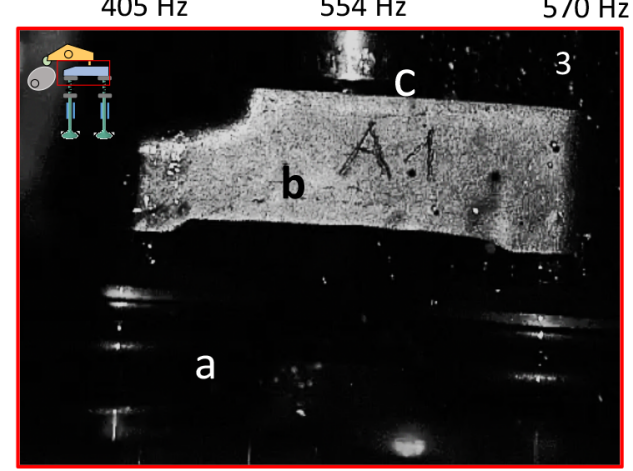

Fig. 12. Characterization of the spring response, (1) natural frequency of resonance of the spring with the mass of the valve applied to the top of the spring, (2) fundamental frequencies from the accelerometer attached to the valves, (3) visualization of the valve actuation with the high-speed camera, a: spring, b: bridge, c: rocker arm.

The local influence of the increase in impact speed will be quantified from a mechanical point of view in Section 3. At this stage, the increase in kinetic energy during impact cannot explain the increase in wear caused by alignment problems.

\subsubsection{Sliding}

The impact is followed by a sliding phase of the valve against the seat. Based on the rigid body model, the relative displacement of an arbitrarily point on the valve determines the amount of slip between the valve and the seat along the contact plane. Misalignments are set between $0 \mu \mathrm{m}$ and $240 \mu \mathrm{m}$ in the ADAMS model (Fig. 11). For perfect alignment, the tilting dynamics of the valve train generates a sliding length of $13.8 \mu \mathrm{m}$. For $100 \mu \mathrm{m}$ of misalignment (maximum tolerance), the slip length is $33.2 \mu \mathrm{m}$. Finally, for $240 \mu \mathrm{m}$ of misalignment, the sliding length is $71.8 \mu \mathrm{m}$.

The increased misalignment results in increased valve sliding on the seat. Despite exceeding the alignment tolerance $(100 \mu \mathrm{m}$ in the specification against $240 \mu \mathrm{m}$ in the ADAMS software), the slip length remains less than $80 \mu \mathrm{m}$. The increase in slip length cannot be related to the increase in wear levels. The finite element model (Sect. 3) will determine the stresses involved when the valve slides against the seat.

\subsubsection{Contact vibrations}

Through the use of the rigid body model and the valve movement platform, it has been possible to demonstrate a local vibration that occurs under certain operating

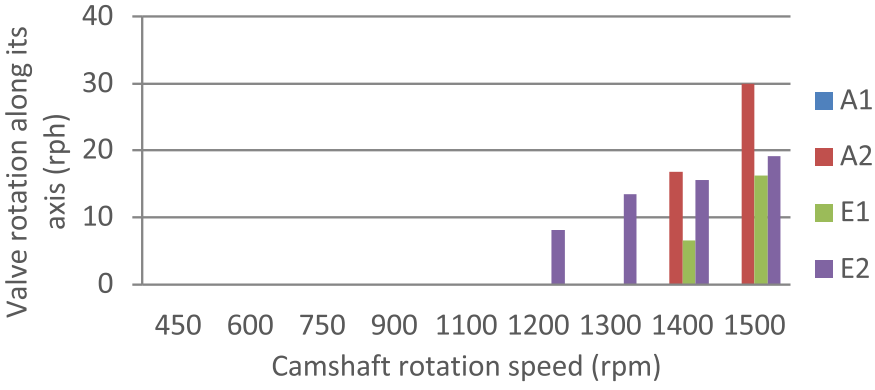

Fig. 13. Determination of valve rotation speed in function of camshaft rotation speed depending of valve position in the cylinder (A1: intake 1, E1: exhaust 1, etc.).

conditions. Figure 12-2 shows the fundamental frequencies from the accelerometer attached to the valve. The accelerometer is powered only from $450 \mathrm{rpm}$ in a frequency range varying from $360 \mathrm{~Hz}$ to $590 \mathrm{~Hz}$. Appropriate frequency responses of the valve, the valve plus its guide and the spring have been determined. The natural resonance frequencies of the spring (Fig. 12-1) are those which correspond best to the signals extracted from the test bench.

Observations of the spring (Fig. 12-3) using an ultrafast camera make it possible to visualize the resonance of the spring inducing the movements of the valve stem. This spring actuation begins at a speed of $600 \mathrm{rpm}$ of the camshaft which corresponds to a speed of $1200 \mathrm{rpm}$ of the engine. The last point that remains to be dealt with is therefore the rotation of the valve. 


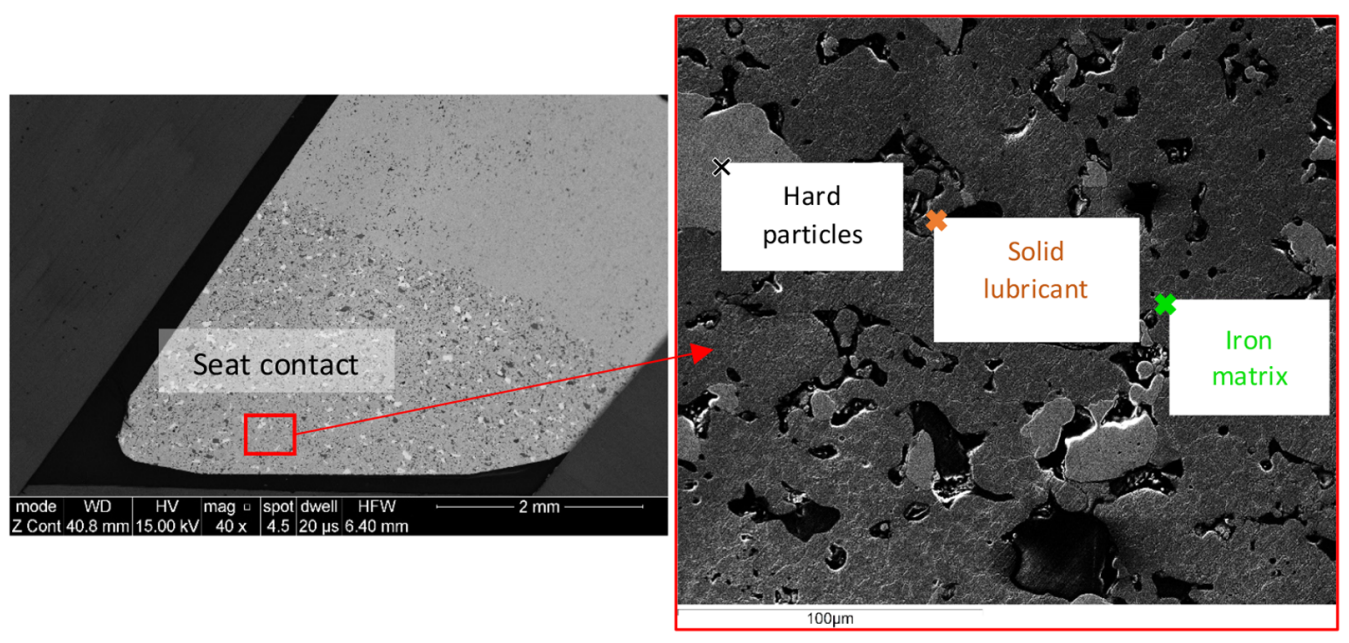

Fig. 14. Sintered seat material structure.

\subsubsection{Valves rotation}

In the literature, authors often associate the rotation of the valve with the level of wear, without consensus on its exact role. If wear particles are blocked in contact, this should limit the potential wear by abrasion. The opposite point of view consists in saying that the rotation of the valve ensures a homogenization of the wear and limits the formation of hot spots [8-10]. We use a consumer camera to assess whether the valves are rotating with the increasing speed of the camshaft. The graph in Figure 13 gives the results for the different camshaft speeds and shows that the rotation is random as a function of the position for values greater than $1200 \mathrm{rpm}$. With this dynamic analysis it not possible to conclude whether the rotation of the valve induces changes in wear.

\subsection{Valve-seat contact dynamic synthesis}

Valve movement is imposed to meet combustion requirements. The combination of a rigid body model and a valve motion platform allows the following steps to be accurately described:

- Closing of the seat-valve contact causes a shock. The parameter conventionally set to avoid the risk of significant degradation is the impact speed. In practice, the speed can reach a value of $1200 \mathrm{~mm} / \mathrm{s}$ for the maximum engine speed $(2800 \mathrm{rpm})$ which is greater than the criteria of $500 \mathrm{~mm} / \mathrm{s}$ found in the literature. A criterion limiting the impact speed is useful to avoid a significant increase in the energy to be dissipated in the contact.

- The sliding is the step following the impact phase. In the ideal case without clearance, no slippage should occur. The increase in the misalignment between the valve guide and the seat induces an increase in the sliding length.

- The rotation of the valve is not controlled in the system.
Dynamic analysis alone cannot answer the whole problem of valve seat degradation. This dynamic is taken up in Section 3 as a boundary condition of the finite element model to determine the local response of the $1^{\text {st }}$ bodies.

It is necessary to determine the local response of the $1^{\text {st }}$ bodies in the contact. To do this, a dual experimental and numerical approach is considered.

\subsection{Description of the $1^{\text {st }}$ bodies involved}

The valve seat is produced by sintering process. The composition of the seat is given in Figure 14. The seat structure is porous with porosity sizes greater than $50 \mu \mathrm{m}$. The particles which constitute the seat contact zone are of three types. The first class is made up of hard particles which are used to strengthen the volume. The second class consists of solid lubricant particles. And finally, most of it is iron (X40Cr-MoNiVNbCa). It is advisable through the tribological study to have information which will explain the functioning of the different compounds in the contact.

The valves are made by forging. The material is stainless steel (X40CrSi-Mo). The surface of the valve is treated by nitriding. Details of the process are not available, however. The result of this nitriding is a homogeneous fusible nitrided layer $10 \mu \mathrm{m}$ thick covering all the valves including the contact zone.

\subsection{Determination of $1^{\text {st }}$ bodies wear characteristics using long and short tests}

2.5.1 Long tests

Analysis of many samples from long term engine tests is difficult due to the wide range of engine operating conditions. The interest of these observations is to reproduce the final state of the surfaces by shorter tests to identify the mechanisms which induced these degradations. Figure 15 shows the intake seat after a durability 

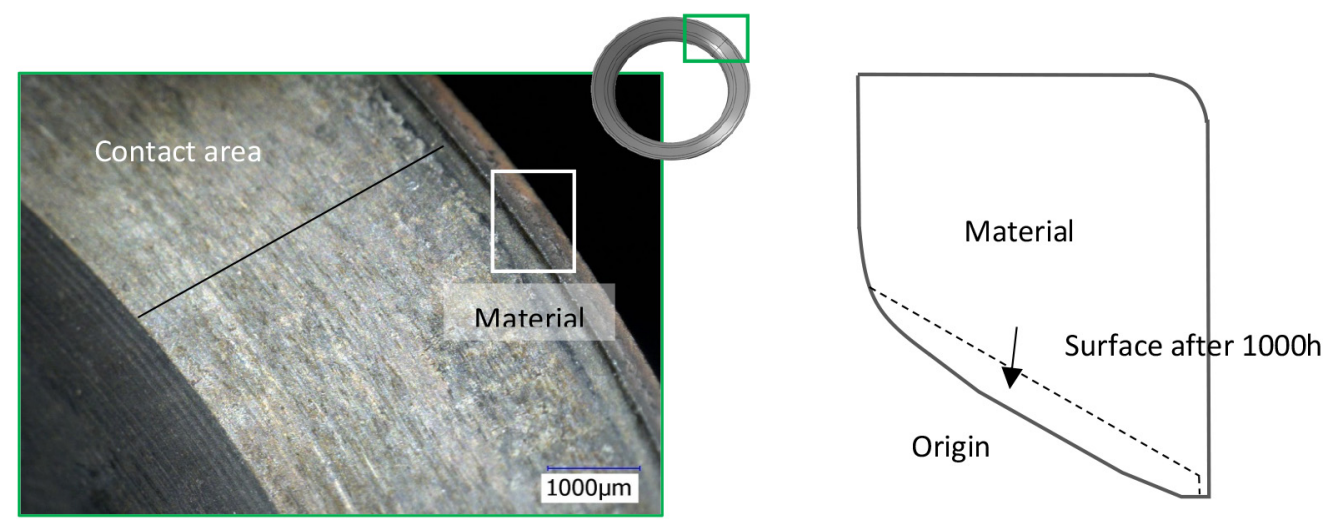

Fig. 15. Seat contact area after 1000 hours of operation.
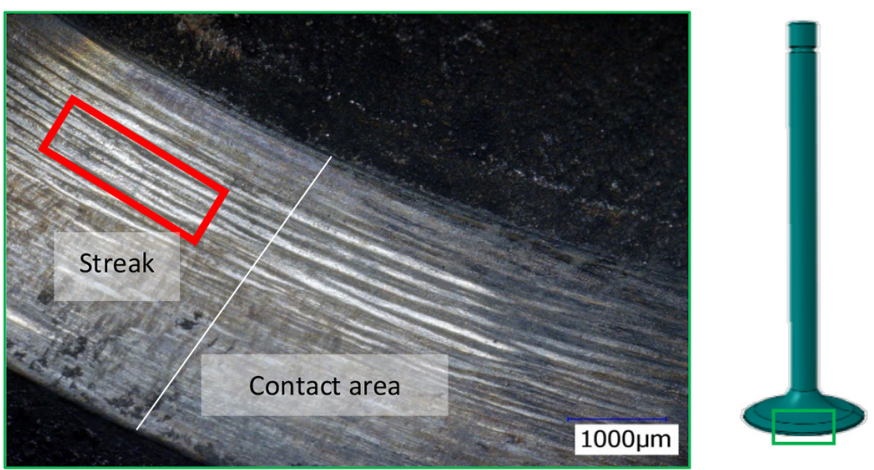

Fig. 16. Valve contact area after 1000 hours of operation.

test. The highlighted contact area is $3.9 \mathrm{~mm}$ wide. The area to the right of the seat photo shows that some of the material has been removed by the repeated contact between the valve and the seat. The diagram of Figure 15 illustrates this phenomenon of enlargement. The area delimited by the solid line (original surface) and the dotted line (surface after 1000 hours of use) corresponds to the seat material which has been evacuated outside the contact. This indicates that the seat is the preferred accommodation site.

Analysis of the opposite side of the corresponding valve (Fig. 16) shows a large contact surface. In this case, the estimated width is $3.6 \mathrm{~mm}$ less than the width of the contact area on the seat. In this same figure, "ridges" are present on the surface of the valve. The wear of the material is located on the seat while the valve is loaded in a heterogeneous manner.

Figure 17 shows a cutout on the seat and on the valve. The image on the top-right shows a hard particle with cracks which is involved in the contact (white area). The hard particles used to reinforce the seat are subject to brittle behaviour. Another mode of accommodation is shown in Figure 17 on the bottom-right. Here the steel matrix is plastically stressed. This plastic flow of the iron matrix of the seat coupled with the brittle fracture of the hard particles of the seat constitute the two modes of accommodation observable. After 1000 hours of testing, the valve (left of Fig. 17) shows that only the fusible nitride layer of the valve is degraded.
Observations of samples after long-term tests do not identify the role of the solid lubricant contained in the seat. To cope with this lack of information, short test samples were carried out.

\subsubsection{Short tests}

To understand the role of the solid lubricant, it is necessary to set up short tests with specific instrumentation (Boher [36]). The study of the valve-seat contact at the inlet gives the reasons why the solid lubricant does not reduce the wear levels below $400^{\circ} \mathrm{C}$. Figure 18 illustrates the operation of the solid lubricant at $250^{\circ} \mathrm{C}$. Image 1 on Figure 18 shows that the indentations are not visible in the contact area. Magnification in the contact area (Fig. 18-2) confirms this material wear. Using the formula involving the geometry of the Vickers cavity, it is possible to locally access the tear height of the seat material.

$$
\begin{aligned}
h_{\text {tearing }} & =\frac{\tan \theta}{2}\left(d_{\text {initial }}-d_{\text {final }}\right)=\frac{\tan 22^{\circ}}{2}(140.6-59.4) \\
& =16.4 \mu \mathrm{m}
\end{aligned}
$$

In 4 hours of use, the material wear at the bottom of the contact area is $16.4 \mu \mathrm{m}$. In photo 2 , two areas stand out. The first materialized by the spectrum 4 presents discontinuous flows forming a significant roughness which differs from the initial one. The second zone materialized by spectrum 5 consists of powdery calcium particles which result from the tearing of the material which takes place on the seat in the contact zone. These flows are at the origin of a heterogeneous layer on the surface of the seat. Mechanical stresses (impact + combustion) induce the fractionation of the solid lubricant due to its fragility. The latter is then ejected in all directions.

\subsection{Results summary through the mass conservation equation: the tribological circuit}

The tribological circuit was introduced by Berthier [37] and used for many applications [38-41]. It formalizes the equation of the incoming and outgoing flows of the contact. 


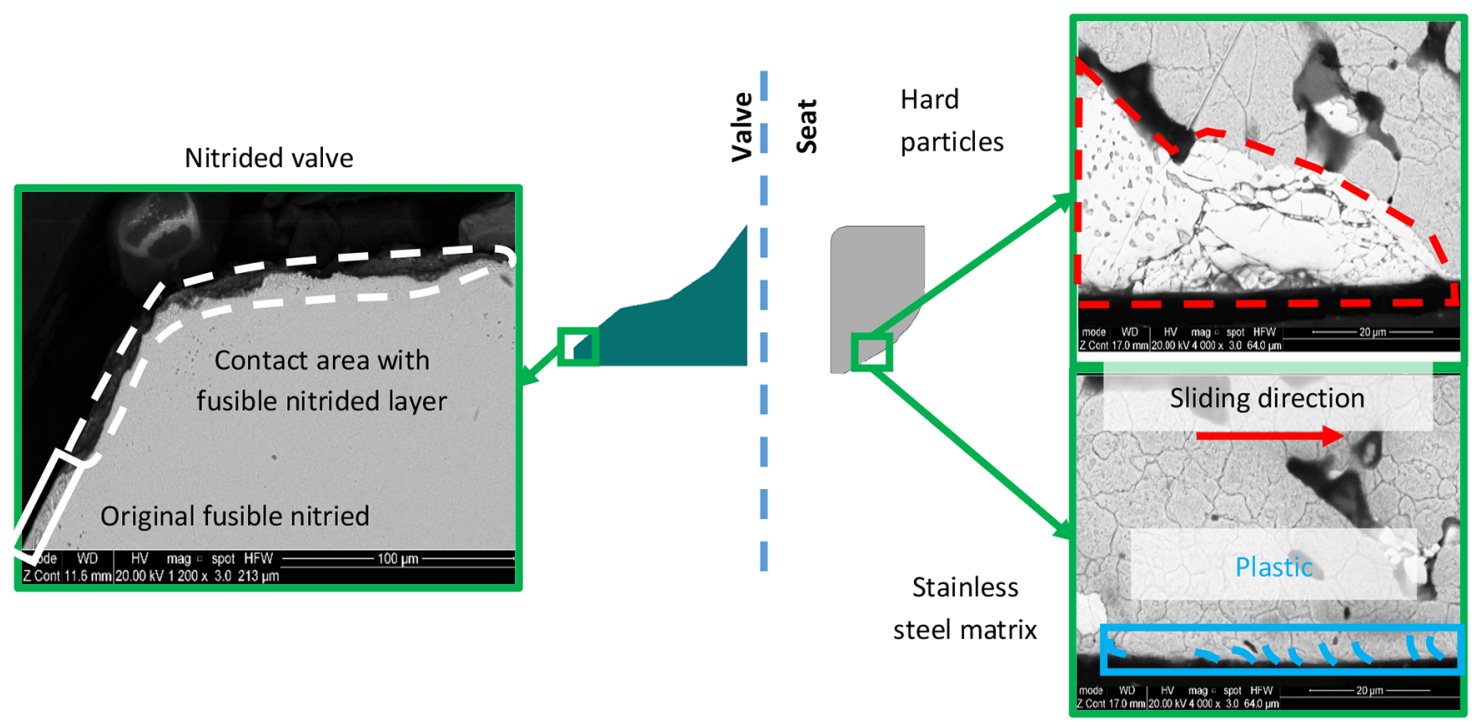

Fig. 17. Sample cuts made after 1000 hours of testing.

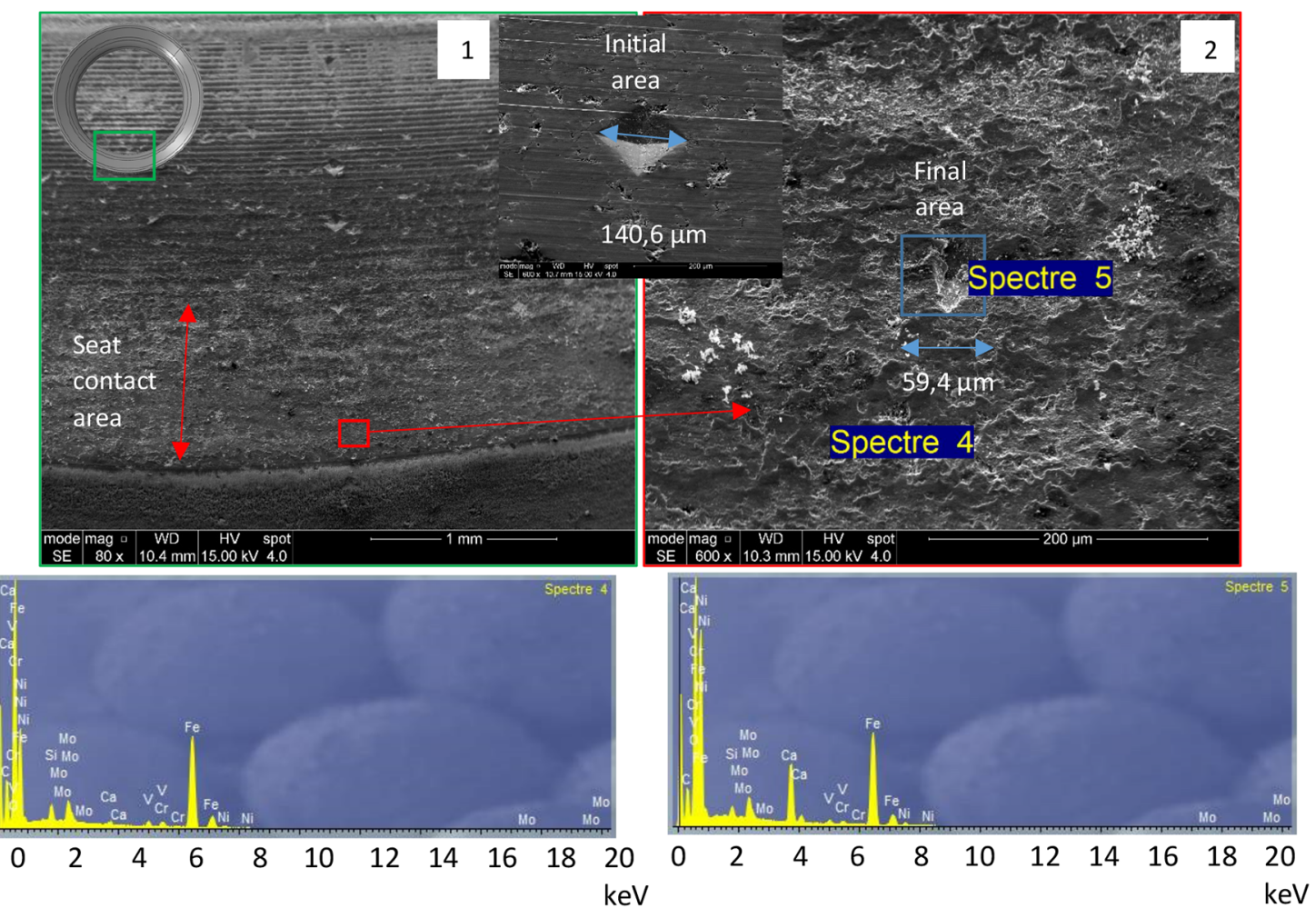

Fig. 18. Inlet seat after 2 hours of operation with fresh air inlet, heating to $250{ }^{\circ} \mathrm{C}, 18.75 \mathrm{~N}$ and impact speed of $650 \mathrm{~mm} / \mathrm{s},(1)$ general view of the contact, (2) magnification in the effective contact area, Spectrum 4 and 5 elementary composition.

From this concept, we can propose corrective actions to limit contact wear. It is possible to identify the modes of accommodation and the flows involved in the tribological circuit (Fig. 19).

The valve is a minor hosting site. The degradation of the fusible nitrided layer of $10 \mu \mathrm{m}$ induces a low flow rate of internal source $\left(Q_{\text {internal_source }}^{\text {Valvenitrided }}\right)$. The seat is the main accommodation site. Wear of the contact material occurs almost exclusively in the seat contact area. Two types of accommodation take place, one by brittle fracture and one by plastic deformation. In the seat, hard particles and solid lubricant, constitute two internal source flows $\left(Q_{\text {internal_source }}^{\text {Seatles }}\right.$ and $\left.Q_{\text {internal_source }}^{\text {Seat_sontidicant }}\right)$. In the seat, the steel matrix deforms plastically $\left(Q_{\text {plastic }}^{\text {Seatrix }}\right)$. The 


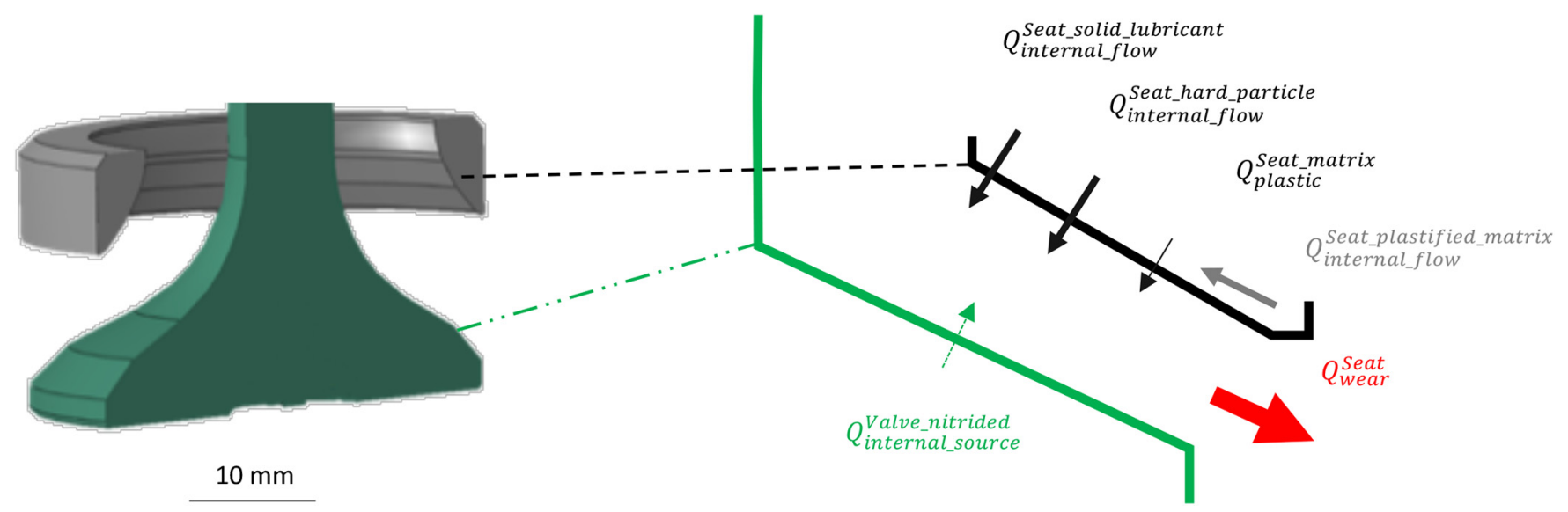

Fig. 19. Summary of flows from $1^{\text {st }}$ bodies.
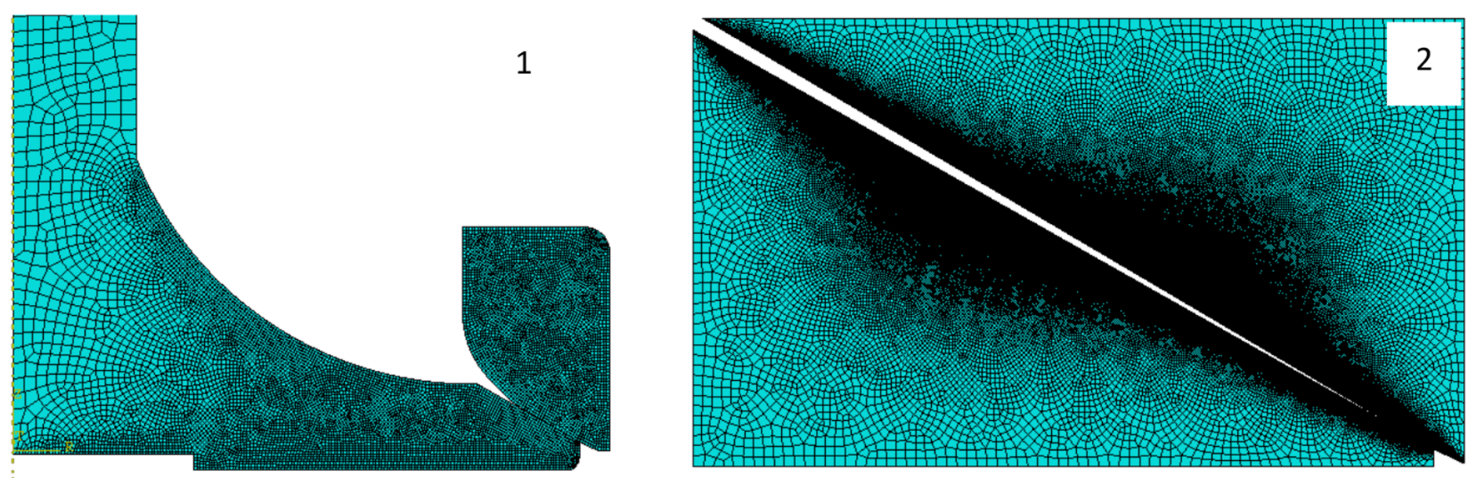

Fig. 20. Mesh of the finite element model in its axisymmetric configuration, (1) global axisymmetric model with large elements, (2) Sub-model with refined mesh.

superposition of plastic deformation cycles results in the formation of an internal source flux $\left(Q_{\text {internal_source }}^{\text {Seat_plastiedix }}\right)$ composed of stranded steel particles. From this material synthesis and the fact that no protection is put in place in the contact, any internal source flow generates the wear flow $\left(Q_{\text {wear }}^{\text {Seat }}\right)$.

The partial equation for the material flows of the first bodies is summarized in Figure 19.

This analysis shows that the elimination of solid lubricant and hard particles limits wear by promoting the plasticity of the matrix. Another way to limit the flow of wear is to limit the mechanical stresses involved in the contact. For this purpose, a finite element model is used.

\subsection{Finite element model to limit contact mechanical solicitations}

The geometry of the valve-seat contact is characterized by its small size. The measurement of local contact pressures is experimentally difficult to set up. Thus, the digital instrumentation through the finite elements proposed in the Abaqus software is a solution to access new information.
Table 4. Input data applied as part of the finite element model.

\begin{tabular}{ll}
\hline Impact speed $(\mathrm{mm} / \mathrm{s})$ & Cylinder pressure $(\mathrm{MPa})$ \\
\hline 200 & 6 \\
300 & 8 \\
400 & 10 \\
500 & 12 \\
600 & 14 \\
700 & 16 \\
800 & 18 \\
900 & 20 \\
1000 & 22 \\
1100 & 24 \\
1200 & 26 \\
\hline
\end{tabular}

\subsubsection{Presentation of the elastic finite element (EF) model}

The finite element model is chosen to characterize the responses of the $1^{\text {st }}$ bodies. Different calculation strategies can be used to treat the problems linked to contacts as 

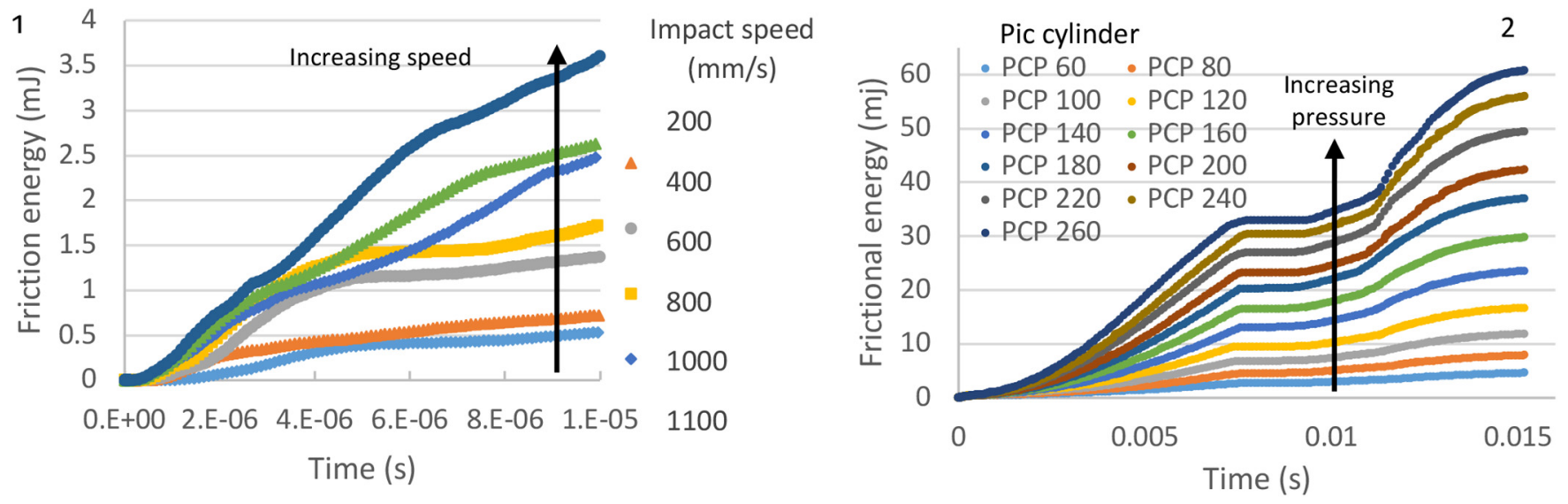

Fig. 21. Friction energies comparison between the impact (1) and the combustion (2).

described in [38] (penalty [42-46], Lagrange multipliers [47-50] and Augmented Lagrangian [51-53]. In the case of the valve-seat contact we choose the latter one.

To manage the size of the contact surface, the computation consists in carrying out a total axisymmetric model of the seat and on the valve with large elements (Fig. 20-1). Then, the boundary conditions resulting from this first stage of calculation are injected into a sub-model of reduced dimension $3 \times 3 \mathrm{~mm}$ refining the mesh (Fig. 20-2). The elements used are of type CAX8 (quadrilateral axisymmetric biquadratic formulation with 8 nodes). Due to the complexity of the geometry, the elements CAX6 complete the elements CAX8 (axisymmetric quadratic pyramid with 6 nodes). An implicit numerical scheme is used.

\subsubsection{Data for the valve-seat contact}

The operating conditions and limits used are as follows:

- Speed of impact applied resulting from the calculations of the model of rigid body.

- Combustion pressure defined according to the maximum pressures measured within the engine for various operating conditions.

- Integrated seat in the area normally dedicated to the bracing of the cylinder head.

- In the chosen configuration, the valve moves only along the direction of the valve stem.

Based on the rigid body model, the impact speed evaluation is $200 \mathrm{~mm} / \mathrm{s}$ for an engine speed of $900 \mathrm{rpm}$ and $1200 \mathrm{~mm} / \mathrm{s}$ for an engine speed of $2800 \mathrm{rpm}$. The speeds shown in Table 4 are applied to the valve to determine the response of the first two bodies during the shock-slip movement.

The same model is used when applying combustion pressure. The pressure varies between 6 and $26 \mathrm{MPa}$ (Tab. 4) to cope with all engine operating conditions. Under all model conditions, a friction indicator of 0.2 is used.

\subsubsection{Comparison criterion for the choice of contact geometry}

To determine which contact geometry is the best to limit mechanical stresses a comparison is made between the

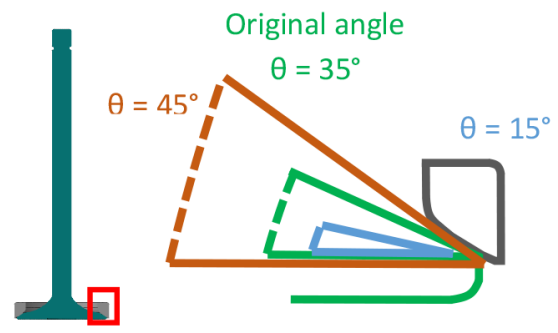

Fig. 22. Definition of the different contact angle used in the finite elements model to modify mechanical contact response.

friction energies involved during the impact and during the combustion (Fig. 21).

From Figure 21-1 we note that the friction energy increases with the speed of impact. The energy varies between $0.7 \mathrm{~mJ}$ for an impact speed of $200 \mathrm{~mm} / \mathrm{s}$ and $3.6 \mathrm{~mJ}$ for a speed of $1200 \mathrm{~mm} / \mathrm{s}$. In Figure 21-2 the energy dissipated by friction increases with the increase in cylinder pressure. A first increase linked to the first phase of application of the combustion pressure and then for the highest pressure, the relative movement of the valve towards the seat is zero and the energy is constant. Finally, when the contact is discharged, a further increase in pressure occurs due to the deformation of the valve. When applying combustion pressure, the friction energy for the minimum pressure of $6 \mathrm{MPa}$ is $4.6 \mathrm{~mJ}$. This value is greater than that generated during impact at the maximum speed of $1200 \mathrm{~mm} / \mathrm{s}$. It can be concluded that the most restrictive stress on contact is the combustion pressure. This criterion will be used to define the geometry of the contacts which will limit the mechanical stresses.

\subsubsection{Change of the contact angle}

The contact angle is a lever to modulate the mechanical contact response. A range from $15^{\circ}$ to $45^{\circ}$ comprising the original angle of $35^{\circ}$ is selected (Fig. 22).

The maximum contact shear stress and the maximum contact pressure (Pmax) are taken from the finite element model for a combustion pressure of $18 \mathrm{MPa}$ under the valve (Fig. 23). The increase in the contact angle to $45^{\circ}$ (compared to the original angle of $35^{\circ}$ ) leads to their 


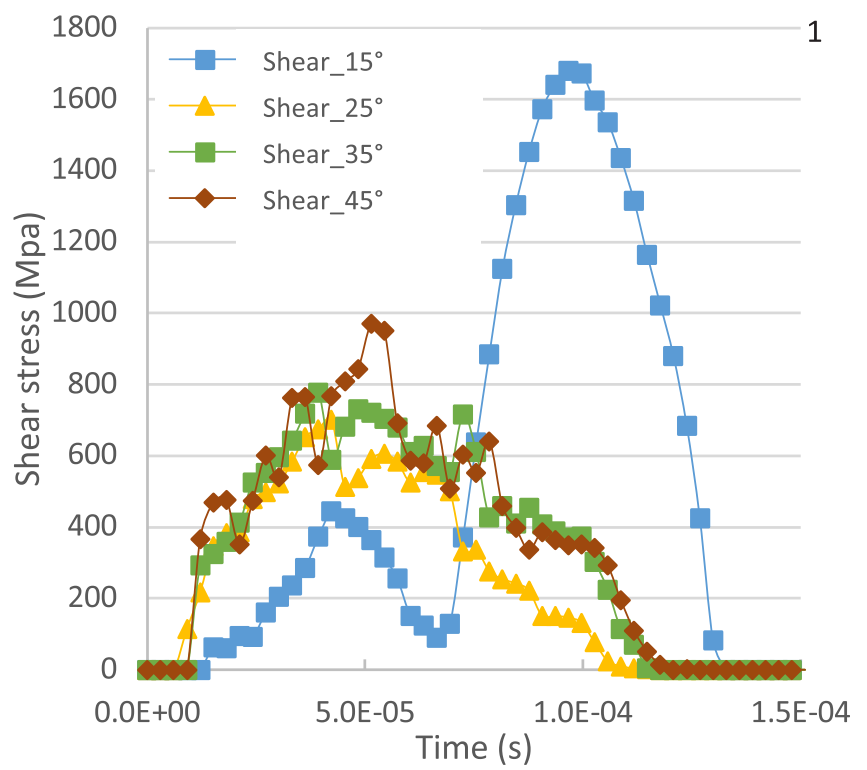

Fig. 23. Valve-seat contact shear stress

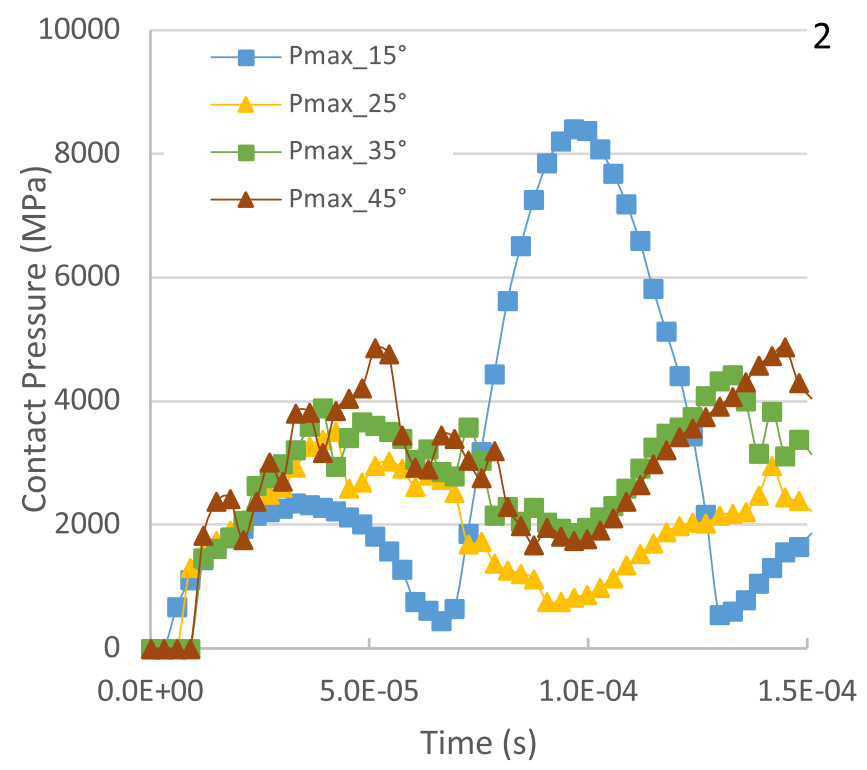

(1) and pressure (2) for different angles. increases. The $25^{\circ}$ angle limits the mechanical stresses involved in the contact. Under the conditions described, the best angle is $25^{\circ}$ instead of the original $35^{\circ}$ angle. The final goal of this change of geometry is to limit the wear of the $1^{\text {st }}$ bodies. The control of this wear must be done by an experimental validation.

Based on the tribological analysis, two possibilities were highlighted in order to limit the wear of the valve seat contacts. First of all, it is possible to determine the behaviour of the material in the actual application. Second, changes in the geometry of the contacts can limit mechanical stresses and thus limit contact wear. A third possibility to limit the wear of the valve seat contact will be described in the next section.

\section{$33^{\text {rd }}$ body interfacial element}

To overcome the difficulty of studying the formation of the $3^{\text {rd }}$ body, a test bench specially adapted to seat-valve contact has been developed within LaMCoS. This test bench will make it possible to identify the mechanisms of formation of the $3^{\text {rd }}$ body according to the different sources of material in contact.

\subsection{Development of a new parametric test bench}

The "Cube" (Fig. 24) is a LaMCoS device. It is used for the reproduction of vibratory phenomena applied to edge elements fixed to the skirt (in yellow Fig. 24). Inside this metal skirt, three pairs of hydraulic jacks allow movement in three directions in space. In addition, slight rotation and slight tilt in all directions is possible.

This equipment can reproduce the mechanical stresses in the valve. The general assembly is given in Figure 25. It includes the elements which reproduce the mechanical stresses of the contact and the elements for controlling the thermal and chemical environment of the contact.
The test bench reproduces the combination of impact, combustion pressure and its environment. All the characteristics are given in Table 5 .

\section{$3.23^{\text {rd }}$ body build up}

3.2.1 Fresh air without gas recirculation and contact at $250{ }^{\circ} \mathrm{C}$

The first test corresponds to an admission of fresh air via the turbo without recirculation of the exhaust gases which results in a contact temperature of $250^{\circ} \mathrm{C}$. After 4 hours of "Cube" experience ( $2 \mathrm{~h}$ in a full engine seat) the sample is shown in Figure 26.

In this configuration, the contact zone is the same as in Figure 18. Image (1) shows that the indentations are not visible in the contact zone. The magnification of the contact area (2) shows the material wear flow. In this photo (2), two areas stand out. The first (spectrum 4) shows discontinuous flows forming a significant roughness which differs from the initial one. The second (spectrum 5) consists of powdery particles consisting of calcium. They result from the tearing of the material that takes place on the seat in the contact area. These flows are at the origin of a heterogeneous and noncovering layer on the surface of the seat. From these observations, one can say that the mechanical stresses (impact + combustion) give rise to the fractionation of the solid lubricant because of its fragility. This solid lubricant is then ejected in all directions. This phenomenon is visible on the "Cube" because the air flow on contact is less important than in the engine and especially at low pressure. In the case of the engine, it is difficult to confirm this phenomenon because the particles are blown directly outside the contact into the combustion chamber.

\subsubsection{Fresh air and contact at $350{ }^{\circ} \mathrm{C}$}

The second test corresponds to an intake of fresh air at a temperature of $350^{\circ} \mathrm{C}$. After 4 hours of the "Cube" 

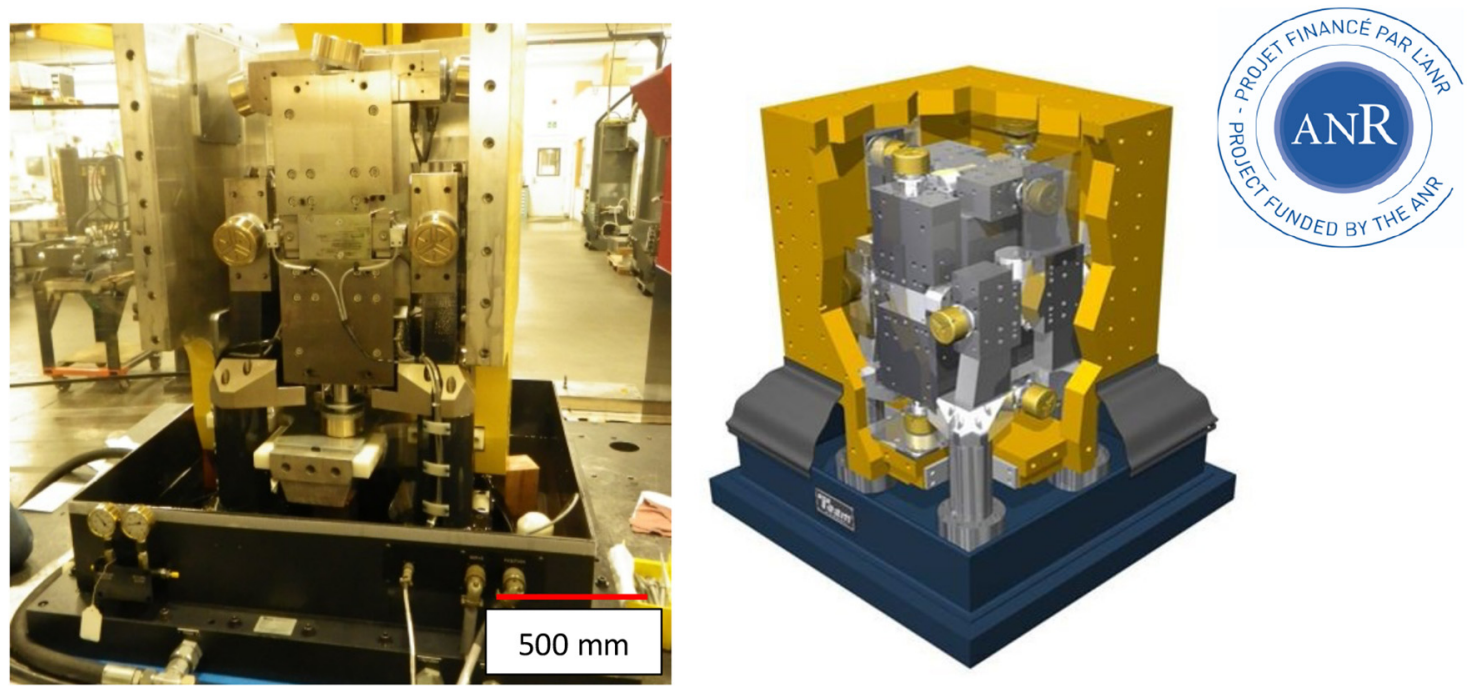

Fig. 24. Illustration of the "Cube" with the cylinders mounted on hydraulic bearings allowing movement and the application of mechanical forces.
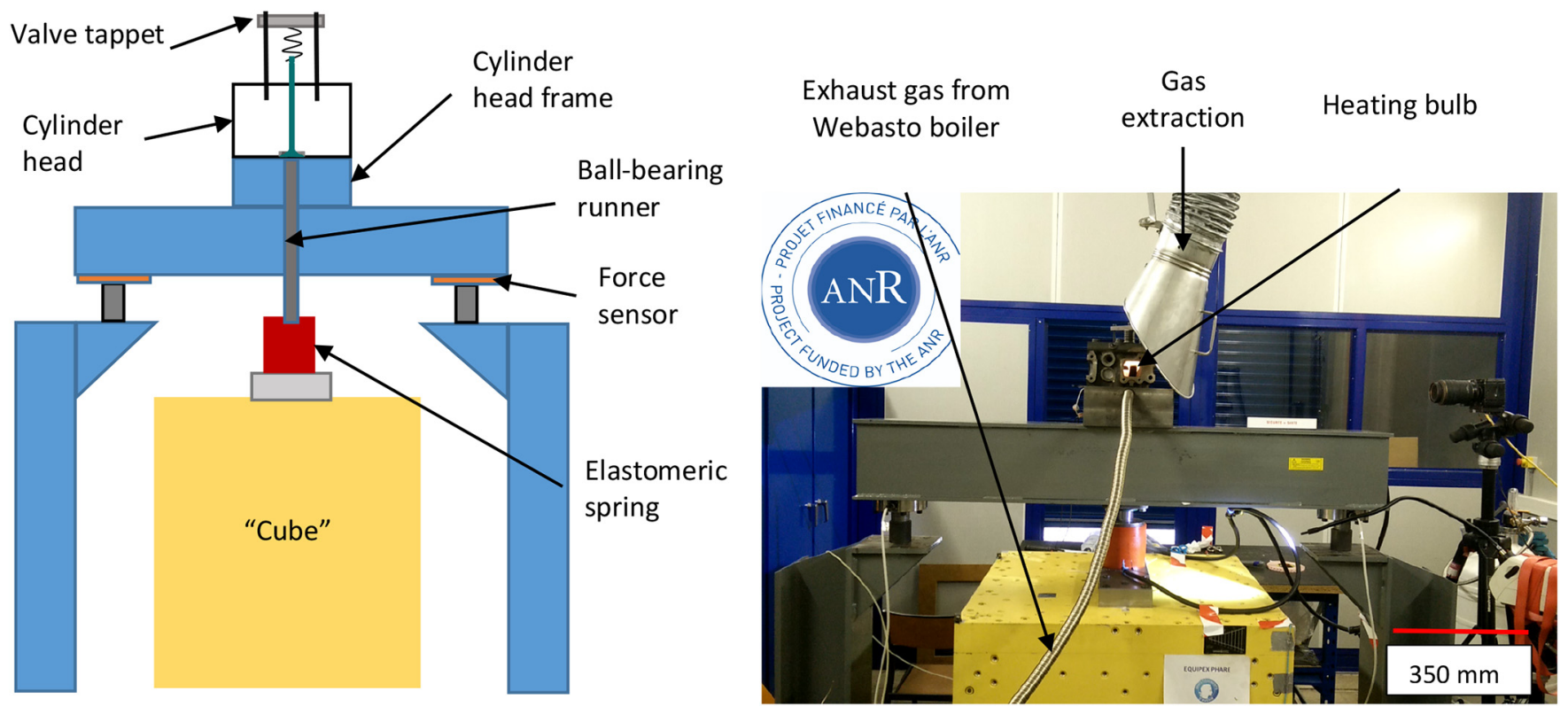

Fig. 25. Experimental setup performed on the "Cube" for tribological analysis of the valve-seat contact.

experiment, the seat sample is presented in Figure 27. For $350{ }^{\circ} \mathrm{C}$, the wear of the material is almost zero. The temperature increases even below $400{ }^{\circ} \mathrm{C}$ (corresponding to the brittle ductile transition of the solid lubricant) allows the solid lubricant to form a $3^{\text {rd }}$ body layer. The pressure at the contact level ensures the implementation of this tribological surface transformation.

The corresponding tribological circuit is given in Figure 28. The increase in temperature induces an internal flow and a $3^{\text {rd }}$ body protection. This protection is evident from the reduced flow of seat wear. Another way to promote the constitution of a $3^{\text {rd }}$ protective body consists of using material sources from the environment. In the case of the diesel engine, it is related to combustion and lubrication.

\subsubsection{Exhaust gas recirculation and burned oil at $250{ }^{\circ} \mathrm{C}$}

The third test corresponds to an admission of combustion gas with lubrication of the valve stem, at a temperature of $250^{\circ} \mathrm{C}$. Question: Can the unburnt species resulting from the combustion or from the residual oil lubrication of the valve stem contribute to the formation of the $3^{\text {rd }}$ body? The seat resulting from the 4 hours test on the "Cube" is 
Table 5. Parameters of tests carried out on the "Cube".

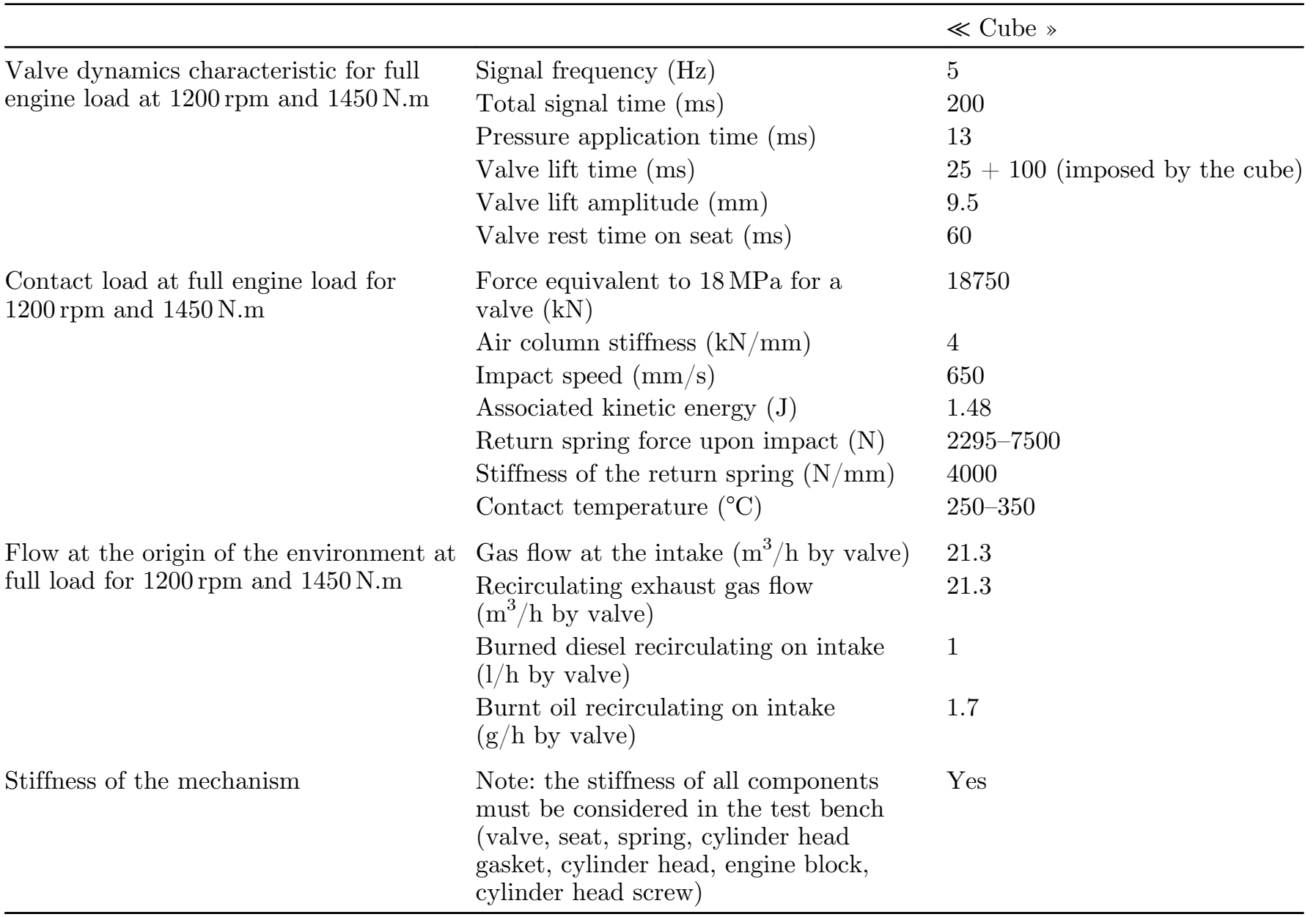
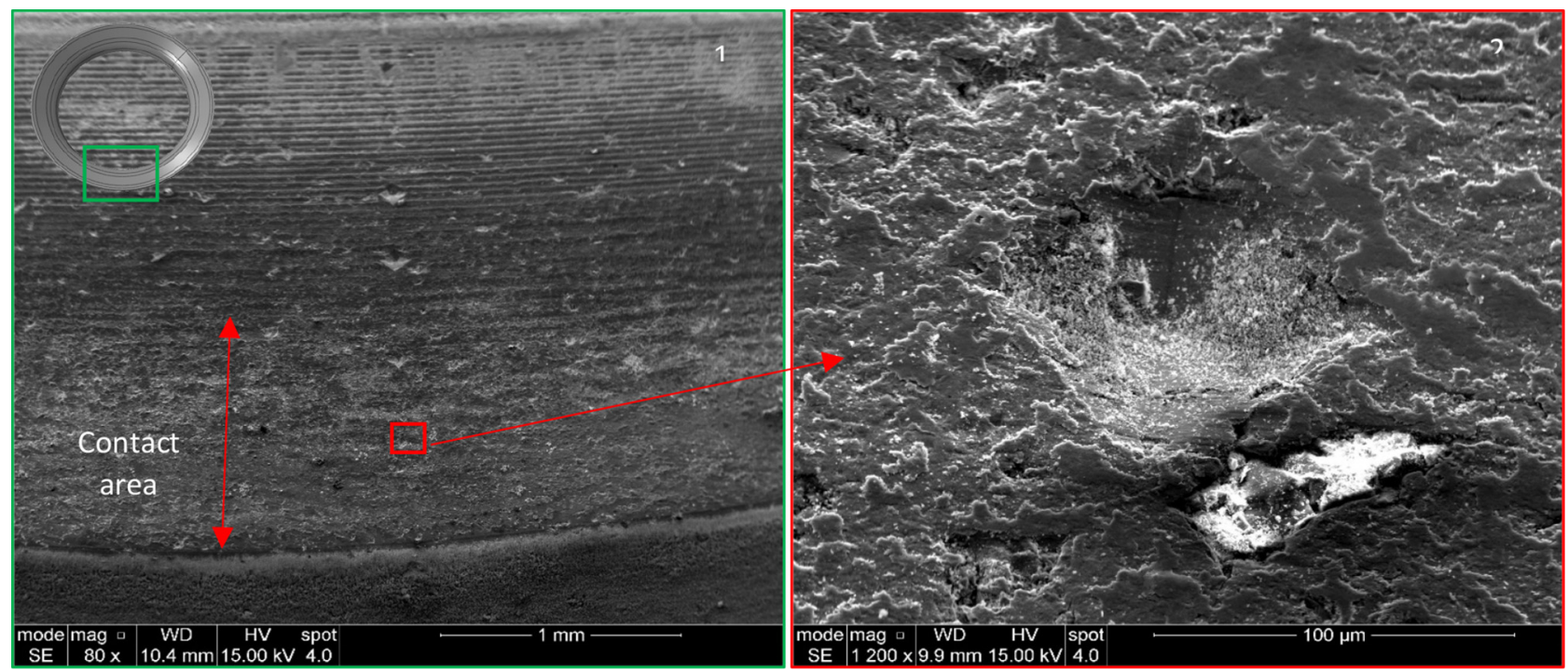

Fig. 26. Intake seat after 4 hours of operation on the "Cube", without exhaust gas but with fresh air intake, heating to $250{ }^{\circ} \mathrm{C}, 18,750 \mathrm{~N}$ and impact speed of $650 \mathrm{~mm} / \mathrm{s}$, (1) General view of the contact, (2) Magnification in the effective contact area. 


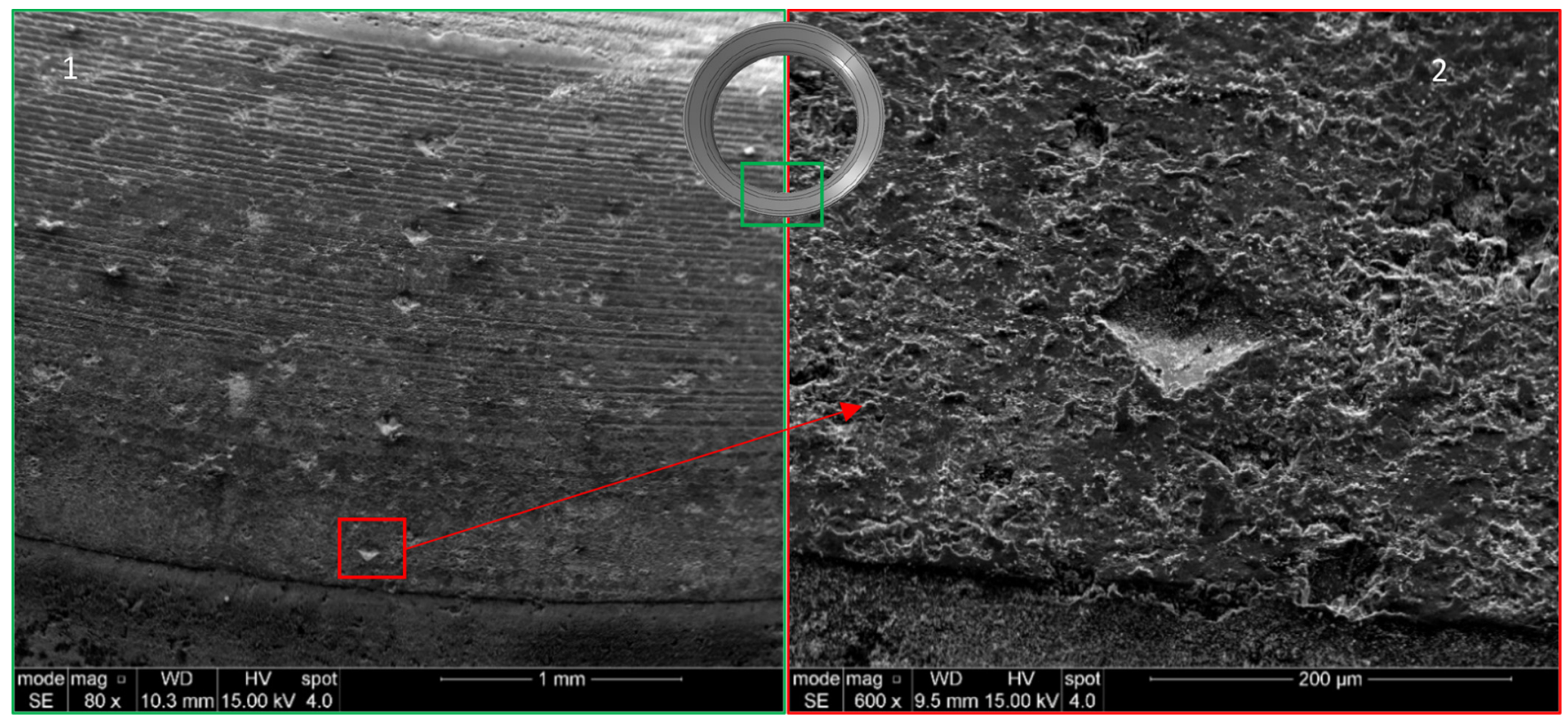

Fig. 27. Seat after $4 \mathrm{~h}$ test on the "Cube, $350^{\circ} \mathrm{C}$, (1) General view of the contact after test, (2) Visualization of the surface marker of the seat in the contact area.

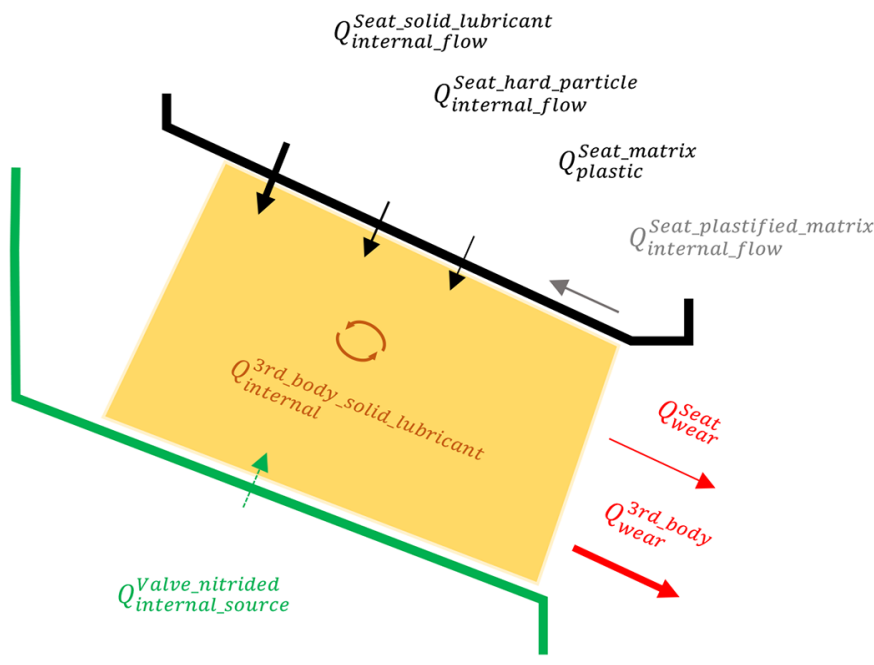

Fig. 28. Tribological circuit in the case of an increase of the inlet contact temperature up to $350^{\circ} \mathrm{C}$ with $3^{\text {rd }}$ body protective action.

shown in Figure 29. The absence of wear of the material can be noted. The magnification in the contact area shows the formation of a $3^{\text {rd }}$ body covering the contact in place of the initial machining grooves. This elementary analysis shows that the oil is at the origin of this protective layer while the unburned hydrocarbons participate in a marginal way.

In the present case, the burnt oil compacted by high contact pressures forms a $3^{\text {rd }}$ protective body (Fig. 30). In this case, the seat wear rate is almost zero:

$$
Q_{\text {wear }}^{\text {Seat }} \approx 0
$$

It is possible due to the external oil source to protect the contact. This protection is ensured if:

$$
\begin{aligned}
& Q_{\text {wear }}^{3 r d \_b o d y \_o i l} \ll Q_{\text {internal }}^{3 r d \_b o d y \_o i l} \text { which is easier to realise if } \\
& Q_{\text {external_source }}^{\text {Oil }} \text { is important. }
\end{aligned}
$$

In practice, to limit health and environmental problems, it is impossible to burn a large quantity of oil in the valve-seat contact zone. To force the formation of the $3^{\text {rd }}$ body from the oil while limiting the quantity involved, a solution is presented in the following paragraph.

\subsection{Modification of the tribological circuit: Inlet seat with oil impregnation, without gas and without oil leakage, $250{ }^{\circ} \mathrm{C}$}

The porous structure of the seat can be used to provide the $3^{\text {rd }}$ body. However, this cannot be done in a controlled and targeted manner using the valve stem seal. To exceed this limit, the seat is impregnated with oil in small quantities and locally. Experimentally, the impregnation process begins with the degassing of the seats under a vacuum of $100 \mathrm{~Pa}$ for 14 hours. Then, the oil used in the engine and the seat to be impregnated is brought to a temperature of $90^{\circ} \mathrm{C}$ for 5 minutes. The seat is then immersed in this oil for 5 minutes. Finally, the samples are left in the open air until complete cooling. The sample is placed on the "Cube" then solicited for 4 hours at $250^{\circ} \mathrm{C}$. at maximum load without adding oil or gas. Figure 31 shows the resulting seat contact area. At the bottom of the seat, under the contact (Fig. 31-1), powdery particles are present in large quantities. EDX analysis (spectrum 1) confirms that it is burnt oil due to the 


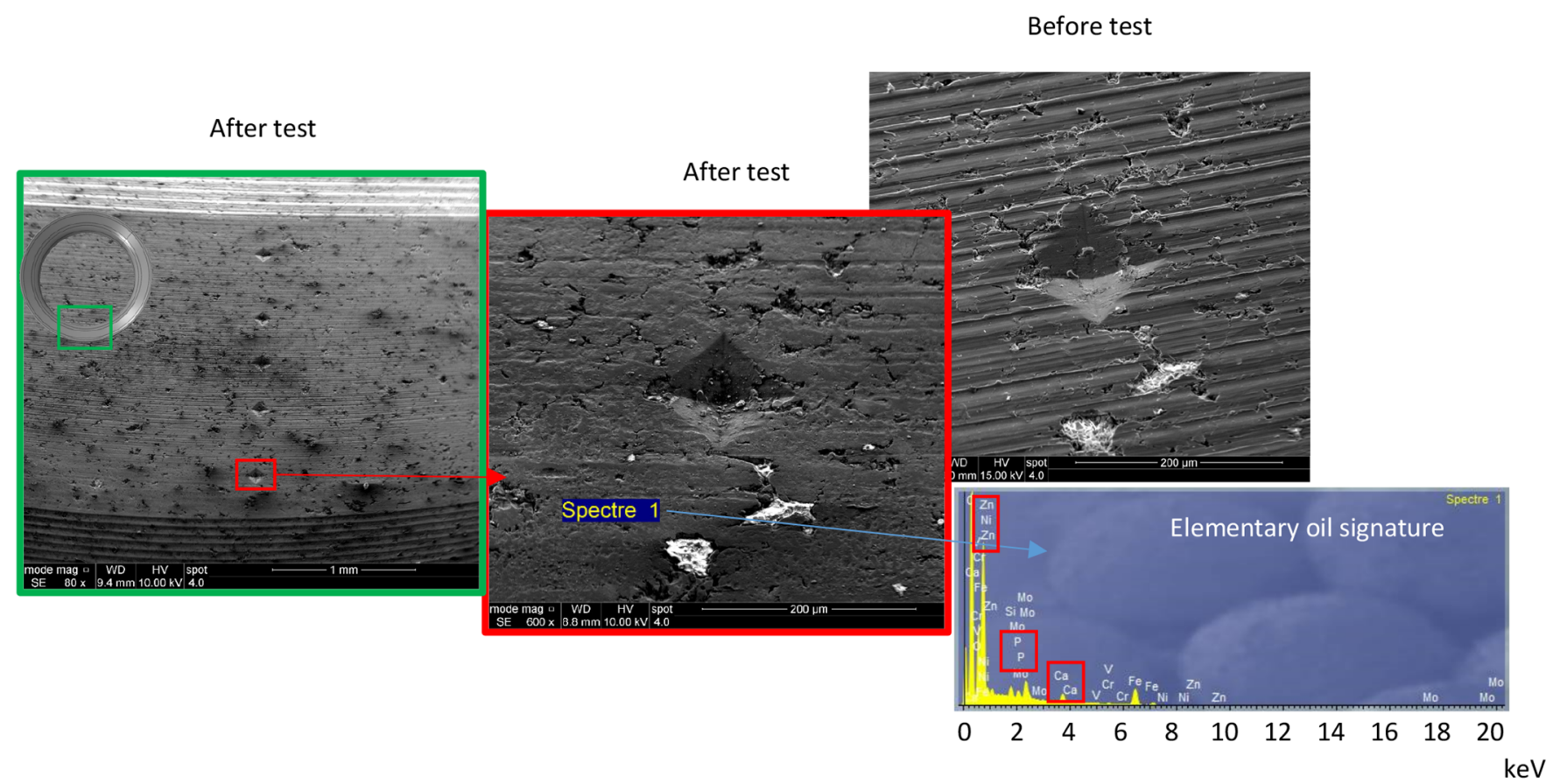

Fig. 29. Final surface of the seat after 4 hours of testing on the "Cube" in the case of an oil supply in the contact via the valve stem and with combustion gas circulation.

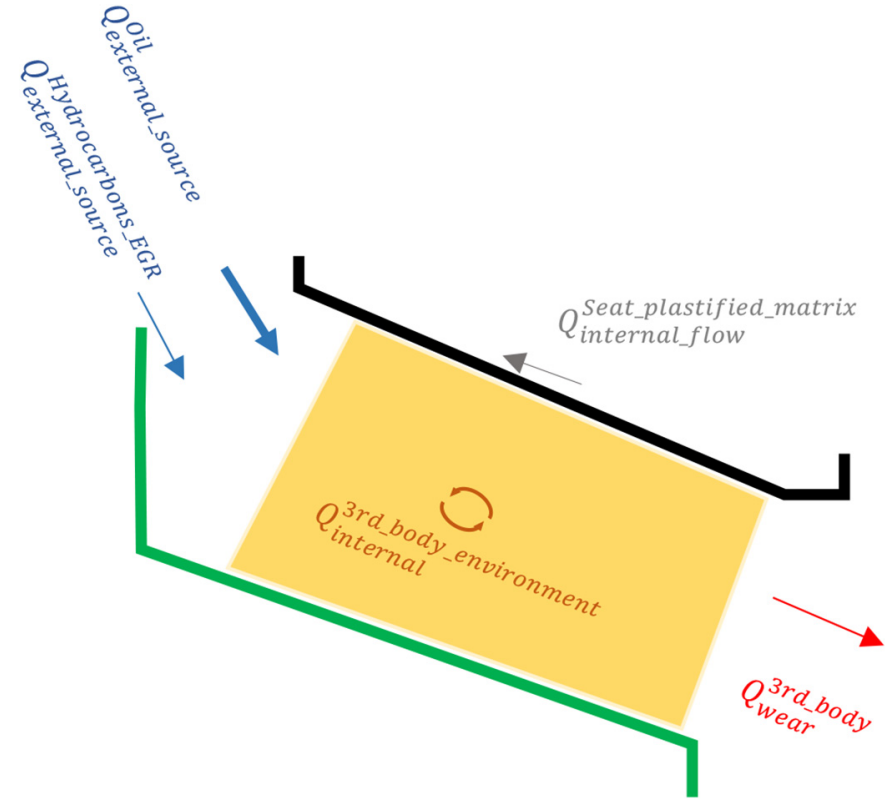

Fig. 30. Tribological circuit with external source flow and for a temperature of $250^{\circ} \mathrm{C}$.

presence of zinc, phosphorus and calcium. This material present in large quantity forms a $3^{\text {rd }}$ protective body on the surface of the seat as illustrated in Figure 31-2. In the contact zone, no wear of the material is visible. The surface is completely homogeneous and covered by the $3^{\text {rd }}$ body.

\section{Conclusions}

Centered both on the dynamics of the mechanism and the material flows at the intake valve-seat contact interface, this multi-scale study allows to identify the main parameters affecting its wear for each scale of the tribological triplet.

The first scale is related to the overall dynamics of the valves. The impact velocity of the valve must be controlled but it is not the only one. The alignment of the assembly is also essential in order to limit the sliding distance. In addition, the rotation of the valves must be controlled in order to limit the random behaviors from one valve to another even in the same engine. The best way to do this is therefore to block the rotation of the valves for diesel engines at low speed.

The second scale is linked to the $1^{\text {st }}$ bodies materials. To limit the wear of the valve seat material, it is necessary to increase the capacity of the contact to dissipate energy and also to limit the incoming energy. To increase such a capacity, it is shown that plastic deformation is the best way. To limit the incoming energy, the angle of the valve seat must be optimized.

Finally, the third scale is linked to the $3^{\text {rd }}$ body. The build-up of a protective $3^{\text {rd }}$ body layer is done by controlling the flow of materials into the contact. The most effective way to quickly build such a protective layer is to force local combustion of a small amount of oil in the contact. 


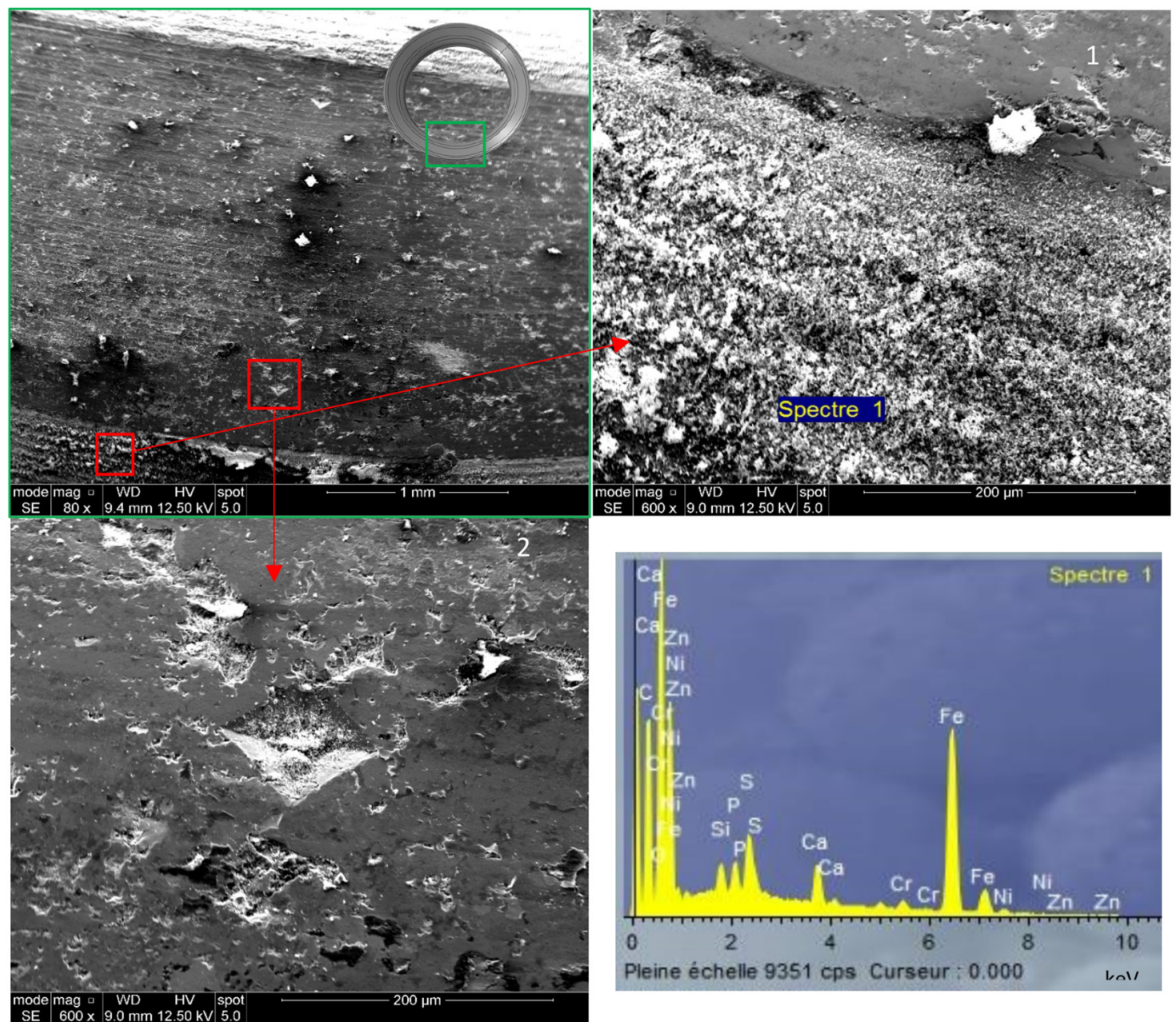

Fig. 31. Oil impregnation, of the seat porosities, 4 hours of testing on the "Cube", (1) Bottom of the contact area with burnt oil, (2) indentation in the contact area.

Acknowledgment. We would like to thank all members of the Equipex PHARE ( ${ }^{\circ}$ ANR-10-EQPX-43) and also Amandine Paquet, Franck Legrand and Romain Trunfio for their great contribution.

\section{References}

[1] Le parlement européen et le conseil de l'union européenne, REACh en détail | REACH INFO, service national $d^{\prime}$ assistance réglementaire $R E A C H$. https://reach-info.ine ris.fr/reach_en_detail (accessed on 07/15/2019)

[2] S.L. Narasimhan, J.M. Larson, E.P. Whelan, Wear characterization of new nickel-base alloys for internal combustion engine valve seat applications, Wear 74, 213-227 (1981)

[3] D. Pierce et al., High temperature materials for heavy duty diesel engines: historical and future trends, Prog. Mater. Sci. 103, 109-179 (2019)

[4] S. Sinharoy, S.L. Narasimhan, Oxidation behavior of two nickel-base superalloys used as elevated temperature valves in spark ignited engines and diesel Exhaust Recirculation (EGR) applications, in Superalloys 2004 (Tenth International Symposium), 2004, pp. 623-626
[5] T. Ootani, N. Yahata, A. Fujiki, A. Ehira, Impact wear characteristics of engine valve and valve seat insert materials at high temperature (impact wear tests of austenitic heatresistant steel SUH36 against Fe-base sintered alloy using plane specimens), Wear 188, 175-184 (1995)

[6] Y.S. Wang, S. Narasimhan, J.M. Larson, J.E. Larson, G.C. Barber, The effect of operating conditions on heavy duty engine valve seat wear, Wear 201, 15-25 (1996)

[7] R. Zhao, G.C. Barber, Y.S. Wang, J.E. Larson, Wear mechanism analysis of engine exhaust valve seats with a laboratory simulator, Tribol. Trans. 40, 209-218 (1997)

[8] X. Liang, G. Strong, D. Eickmeyer, K. Myers, A new wear tester to determine valve seat insert wear resistance, SAE Technical Paper, 1999

[9] M. Badami, F. Marino, Fatigue tests of un-HIP'ed $\gamma$-TiAl engine valves for motorcycles, Int. J. Fatigue 28, 722-732 (2006)

[10] K.J. Chun, J.S. Hong, Comparison of the wear exerted on engine valves and seat inserts under various speeds and mileages, Proc. Inst. Mech. Eng. Part J. Automob. Eng. 220, 1783-1791 (2006)

[11] L.A.B. Mascarenhas, J. de O. Gomes, A.T. Portela, C.V. Ferreira, Reducing the development life cycle of automotive 
valves and seat valves using a new workbench for high temperature wear testing, Proc. CIRP 29, 833-838 (2015)

[12] J. Choi, J. Lee, N. Jun, C.-S. Seok, S. Park, G. Kim, Development of Laboratory Fatigue Testing Apparatus for Automotive Vehicle Engine Valve Simulating Actual Operating Conditions, Int. J. Precis. Eng. Manuf. 20, 1241-1253 (2019)

[13] C.G. Scott, A.T. Riga, H. Hong, The erosion-corrosion of nickel-base diesel engine exhaust valves, Wear 181-183(2), 485-494, 1995

[14] P.A. Lakshminarayanan, N. Nayak, Y. Aghav, A.D. Dani, Solving inlet valve seat wear problem in high BMEP Engines, presented to SIAT 2001 (2001) doi: 10.4271/2001-26-0024

[15] L. Ara, G.A. De Paula et al., Investigations of Valve Recession Mechanism in Flex Fuel Engines, SAE Technical Paper (2011). Accessed on 12/13/2016, online: http:// papers.sae.org/2011-36-0340/

[16] M.I. Khan, M.A. Khan, A. Shakoor, A failure analysis of the exhaust valve from a heavy duty natural gas engine, Eng. Fail. Anal. 85, 77-88 (2018)

[17] J. Xie, Y. Zhou, M. Tian, Study on continuing airworthiness of reciprocating aeroengine about valve sticking and valve breakage, Proc. Eng. 80, 445-455 (2014)

[18] A. Rivola, M. Troncossi, G. Dalpiaz, A. Carlini, Elastodynamic analysis of the desmodromic valve train of a racing motorbike engine by means of a combined lumped/finite element model, Mech. Syst. Signal Process. 21, 735-760 (2007)

[19] L.P. Boggupalli, An approach to analyze valve train dynamics of an IC engine using software tool 'Tycon', Int. J. Innov. Eng. Technol. 3, 8 (2013)

[20] F. Zenklusen, A. Cardona, C.D. Luengo, F. Cavalieri, J. Risso, Numerical and experimental stress analysis of an internal combustion engine valve during the closing event, J. Automob. Eng. 228(5), 479-489 (2014)

[21] M.Y. Ali et al., Effect of valvetrain components misalignment on valve and guide interactions in automotive engines, SAE Int. J. Engines 10, 668-679 (2017)

[22] L.P. Boggupalli, Investigations on valve recession of a commercial vehicle engine, SAE Int. J. Commer. Veh. 6, 575-581 (2013)

[23] K. Goudarzi, M.H. Shojaefard, M. Fazelpour, Effect of contact pressure and frequency on contact heat transfer between exhaust valve and its seat, Int. J. Eng. 21(4), 401-408 (2008)

[24] M.I. Karamangil, A. Avci, H. Bilal, Investigation of the effect of different carbon film thickness on the exhaust valve, Heat Mass Transf. 44, 587-598 (2008)

[25] A. Hornik, D. Jędrusik, K. Wilk, Unsteady state heat flow in the exhaust valve in turbocharged Diesel engine covered by the layer of the carbon deposit, Arch. Mater. Sci. Eng. 54, 68-77 (2012)

[26] L. Witek, Failure and thermo-mechanical stress analysis of the exhaust valve of diesel engine, Eng. Fail. Anal. 66, 154-165 (2016)

[27] M. Cerdoun, S. Khalfallah, A. Beniaiche, C. Carcasci, Investigations on the heat transfer within intake and exhaust valves at various engine speeds, Int. J. Heat Mass Transf. 147, 119005 (2020)

[28] P. Forsberg, F. Gustavsson, P. Hollman, S. Jacobson, Comparison and analysis of protective tribofilms found on heavy duty exhaust valves from field service and made in a test rig, Wear 302, 1351-1359 (2013)
[29] D. Kesavan, V. Done, M.R. Sridhar, R. Billig, D. Nelias, High temperature fretting wear prediction of exhaust valve material, Tribol. Int. 100, 280-286 (2016)

[30] M. Godet, The third-body approach: a mechanical view of wear, Wear 100, 437-452 (1984)

[31] B. Geoffroy, Distribution à soupapes, Techniques de l'ingénieur, b2805 (1995)

[32] N.V. Orlandea, Multibody Systems History of ADAMS. ASME. J. Comput. Nonlinear Dynam. 11, 060301 (2016)

[33] P. Forsberg, D. Debord, S. Jacobson, Quantification of combustion valve sealing interface sliding - A novel experimental technique and simulations, Tribol. Int. 69, 150-155 (2014)

[34] R. Lewis, R.S. Dwyer-Joyce, An experimental approach to solving combustion engine valve and seat wear problems, Tribology Series, 39, 629-640 (2001)

[35] R. Lewis, R.S. Dwyer-Joyce, Wear of diesel engine inlet valves and seat inserts, Proc. Inst. Mech. Eng. Part J. Automob. Eng. 216, 205-216 (2002)

[36] C. Boher, Réponses aux sollicitations tribologiques d'oxydes métalliques et d'alliages ductiles: organisation de la déformation plastique dans les Transformées Tribologiques de Surface, conséquences sur le débit source de troisième corps, HDR, 2016

[37] Y. Berthier, Experimental evidence for friction and wear modelling, Wear 139, 77-92 (1990)

[38] J. Rolland, A. Saulot, Y. Berthier, Experimental tribological analysis of the Swiss lever escapement, Wear 376-377, 1418-1428 (2017)

[39] A. Saulot, L. Baillet, Dynamic finite element simulations for understanding wheel-rail contact oscillatory states occurring under sliding conditions, J. Tribol. 128, 761-770 (2006)

[40] G. Colas, A. Saulot, C. Godeau, Y. Michel, Y. Berthier, Decrypting third body flows to solve dry lubrication issue MoS2 case study under ultrahigh vacuum, Wear $\mathbf{3 0 5}$, 192-204 (2013)

[41] R. Charlery, Comportements sous sollicitations tribologiques d'un matériau énergétique: Recherche des conditions de contrôle de la sécurité de fabrication, $\mathrm{PhD}$ Thesis, Lyon, INSA, 2014

[42] L. Boulmane, Application des techniques implicites-explicites de la dynamique transitoire a la simulation numerique en mise en forme des metaux, thesis, Besançon, 1994

[43] J.O. Hallquist, G.L. Goudreau, D.J. Benson, Sliding interfaces with contact-impact in large-scale Lagrangian computations, Comput. Methods Appl. Mech. Eng. 51, 107-137 (1985)

[44] M. Pletz, W. Daves, W. Yao, W. Kubin, S. Scheriau, Multiscale finite element modeling to describe rolling contact fatigue in a wheel-rail test rig, Tribol. Int. 80, 147-155 (2014)

[45] F. Lévesque, S. Goudreau, L. Cloutier, A. Cardou, Finite element model of the contact between a vibrating conductor and a suspension clamp, Tribol. Int. 44, 1014-1023 (2011)

[46] D. Perić, D.R.J. Owen, Computational model for 3-D contact problems with friction based on the penalty method, Int. J. Numer. Methods Eng. 35, 1289-1309 (1992)

[47] A.L. Mohd Tobi, P.H. Shipway, S.B. Leen, Finite element modelling of brittle fracture of thick coatings under normal and tangential loading, Tribol. Int. 58, 29-39 (2013) 
[48] W. Ling, H.K. Stolarski, On elasto-plastic finite element analysis of some frictional contact problems with large sliding, Eng. Comput. 14, 558-580 (1997)

[49] C. Meier, A. Popp, W.A. Wall, A finite element approach for the line-to-line contact interaction of thin beams with arbitrary orientation, Comput. Methods Appl. Mech. Eng. 308, 377-413 (2016)

[50] N.J. Carpenter, R.L. Taylor, M.G. Katona, Lagrange constraints for transient finite element surface contact, Int. J. Numer. Methods Eng. 32, 103-128 (1991)
[51] J.C. Simo, T.A. Laursen, An augmented lagrangian treatment of contact problems involving friction, Comput. Struct. 42, 97-116 (1992)

[52] M. Hirmand, M. Vahab, A.R. Khoei, An augmented Lagrangian contact formulation for frictional discontinuities with the extended finite element method, Finite Elem. Anal. Des. 107, 28-43 (2015)

[53] T.Y. Chang, A.F. Saleeb, S.C. Shyu, Finite element solutions of two-dimensional contact problems based on a consistent mixed formulation, Comput. Struct. 27, 455-466 (1987)

Cite this article as: M. Crozet, Y. Berthier, A. Saulot, D. Jones, B. Bou-Saïd, Valve-seat components in a diesel engine: a tribological approach to limit wear, Mechanics \& Industry 22, 44 (2021) 